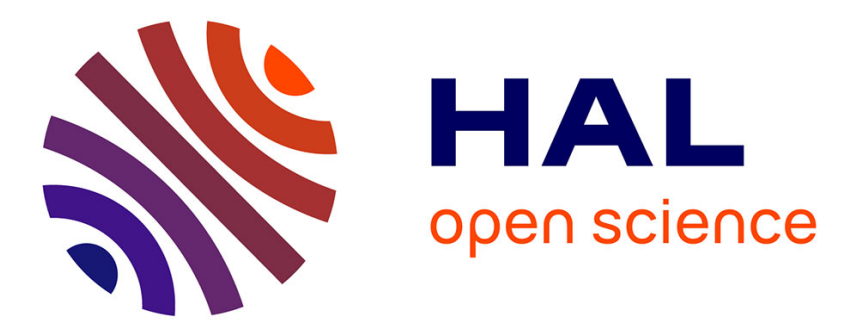

\title{
Electric energy management in residential areas through coordination of multiple smart homes
}

Berk Celik, Robin Roche, Siddharth Suryanarayanan, David Bouquain, Abdellatif Miraoui

\section{- To cite this version:}

Berk Celik, Robin Roche, Siddharth Suryanarayanan, David Bouquain, Abdellatif Miraoui. Electric energy management in residential areas through coordination of multiple smart homes. Renewable and Sustainable Energy Reviews, 2017, 80, pp.260 - 275. hal-02131022

\section{HAL Id: hal-02131022 \\ https://hal.science/hal-02131022}

Submitted on 16 May 2019

HAL is a multi-disciplinary open access archive for the deposit and dissemination of scientific research documents, whether they are published or not. The documents may come from teaching and research institutions in France or abroad, or from public or private research centers.
L'archive ouverte pluridisciplinaire HAL, est destinée au dépôt et à la diffusion de documents scientifiques de niveau recherche, publiés ou non, émanant des établissements d'enseignement et de recherche français ou étrangers, des laboratoires publics ou privés. 


\title{
Electric Energy Management in Residential Areas Through Coordination of Multiple Smart Homes
}

\author{
${\text { Berk Celik }{ }^{\mathrm{a}, *}, \text { Robin Roche }}^{\mathrm{a}}$, Siddharth Suryanarayanan ${ }^{\mathrm{b}}$, David Bouquain ${ }^{\mathrm{a}}$, Abdellatif Miraoui ${ }^{\mathrm{a}}$ \\ ${ }^{a}$ FEMTO-ST, CNRS, Univ. Bourgogne Franche-Comte, UTBM, 90010 Belfort, France \\ ${ }^{b}$ Department of Electrical \& Computer Engineering, Colorado State University, 80523 Fort Collins, Colorado, USA
}

\begin{abstract}
Grid modernization through philosophies such as the Smart Grid has the potential to meet increasing demand and integrate new distributed generation resources at the same time. Using advanced communication and computing capabilities, the Smart Grid offers a new avenue of controlling end-user assets, including small units such as home appliances. To enable such evolution, shifting from centralized to decentralized control strategies is required. Effective demand-side management (DSM) and demand response (DR) approaches hold the promise for efficient energy management in homes and neighborhood areas, by enabling the precise control of resources to reduce net demand. However, with such strategies, independently taken decisions can cause undesired effects such as rebound peaks, contingencies, and instabilities in the network. Therefore, the interactions between the energy management actions of multiple households is a challenging issue in the Smart Grid. This paper provides a review of the background of residential load modeling with DR and DSM approaches in a single household and concepts of coordinating mechanisms in a neighborhood area. The objective of this paper is to classify, via comparison, the various coordination structures and techniques from recent research. The results of recent research in the field reveal that the coordination of energy management in multiple households can benefit both the utility (i.e., the service provider) and the customer. The paper concludes with a discussion on the prevalent critical issues in this area.
\end{abstract}

Keywords: Smart grid, Demand response, Demand-side management, Multiple households coordination, Rebound peak, Residential energy management

\section{Introduction}

Developments in information technologies (IT), control, communication, and associated applications to power engineering have provided the tools for modernizing the traditional electricity grid. The evolution of the Smart Grid heralds a more interactive, distributed, and flexible role for the end-user in the day-to-day operations of the infrastructure [1]. Consumers are provided access to near real-time information and can benefit from technologies such as two-way communication, distributed generation (DG), and schedulable assets, thus changing from passive to active participants in the Smart Grid.

Electricity grid operators respond to the changing demand of consumers by adjusting generation and ensuring the transmission and distribution (T\&D) assets are carrying no more than the rated value of power, efficiently and reliably. Historically, generation capacity was built to accommodate consumption peaks, i.e., the highest demand. But such peaks tend to increase over the years, for example due to population increase and the introduction of new consumption habits and devices (such as the personal computer in the 1990s and the projected electric vehicles growth in the coming decades). Although the increased electricity demand can be met by central bulk generation plants, the T\&D system must also be upgraded — at high costs - to accommodate these higher capacities. On the other hand, distributed energy resources (DER)—which are located

\footnotetext{
${ }^{*}$ Corresponding author
}

in proximity to end-user loads-provide a promising alternative to building new centralized bulk generation capacity and new or upgraded transmission lines.

DER are relatively smaller rated energy sources, with rated capacity ranging from a few $\mathrm{kW}$ in residential buildings to several MW on the distribution grid. DER can also be either conventional (e.g., micro turbines and diesel generators) or renewable energy sources (RES) (e.g., solar photovoltaic, wind turbines and biomass converters). Due to growing concerns of climate change, RES are increasingly preferred to conventional sources.

However, one of the biggest issues of RES integration is their intermittent characteristic [2]. The stochasticity of RES output, combined with the uncertain behavior of the consumer, implies greater difficulties in ensuring a real-time balance between generation and demand for system operators. The uncertainty in availability of generation and demand can be avoided using energy storage, but this solution is currently either prohibitively costly or inefficient at bulk levels or fraught with environmental constraints (such as for pumped hydro storage systems).

Another approach is to increase the flexibility of demandside resources, i.e., the loads. This may be done by controlling end-user appliances, e.g., through home energy management systems (HEMS). Such approaches require extensive, reliable information on the whole system. This information can be made available through information and communication technologies (ICT), typically using sensors and supervisory control and data acquisition (SCADA) on the T\&D system. For ex- 
ample, between end-users and the utility, smart metering and real-time data processing enable bidirectional communication though the advanced metering infrastructure (AMI) [3]. This in turn enables monitoring and control of resources such as DG and storage, which may then result in reverse energy flows, from consumers to the utility. Through such local resources, end-users are thus able to actively participate in electric network operations. This is a major shift from the traditional bulk power generation paradigm, as many more small-scale producers are expected to connect to the grid.

Demand response (DR) is a flexibility mechanism that enables consumer participation to demand modulation in response to a signal from the system operator [4]. Participation is enabled by optimizing the operation of local resources, such as electric appliances. Although HEMS programs propose promising solutions for better and ideally simpler energy management in smart homes, uncoordinated management may cause unexpected results, and may paradoxically lead to unstable operations or higher costs, such as rebound peaks $[13,14]$. To avoid this situation, efficient and robust coordination mechanisms are key elements in the designed energy management systems. Coordination may here be defined as a process enabling a set of entities (here, smart homes, utilities, aggregators) to organize their actions to work together effectively. This paper therefore primarily focuses on the flexibility of demand and the attached coordination mechanisms in residential neighborhoods-defined as a group of up to several dozen or hundred smart homes.

Various DR methodologies and programs were reviewed in the literature. In [5], HEMS and DR programs are reviewed for the single household environment. In [6], the psychological and economic behaviors of consumers for residential DR are analyzed. In [7], the impact of technological developments in the smart home area and on consumer behavior are investigated. In [8], household appliances are categorized to investigate their effect on DR programs. In [9], building energy modeling is reviewed by investigating optimal control models for single and multiple smart houses. In [10], a comprehensive survey reviews and classifies DR algorithms for the residential, commercial and industrial sectors according to the utilized pricing and optimization methods. The structure (centralized and distributed approaches) of the proposed methods is also considered; however the coordination of groups of houses is not discussed. In [11], DR algorithms for the residential sector are presented with a review of the latest scheduling methods and communication techniques. Finally, in [12], multiple DR programs are reviewed with a focus on their interactions with RES.

The above literature survey shows that although numerous management systems and techniques have been proposed and investigated, literature on coordination mechanisms at the smart neighborhood level has not yet been studied in details. This paper aims to fill this gap and provides a review and analysis of coordination mechanisms for energy management of multiple households. Several aspects are considered in the survey, including coordination structures (which entities interact with each other and how) and techniques (how decisions are taken). Through this paper, the authors aim to provide the reader with an overview of the state-of-the-art of such coordination mecha- nisms. Trends in research activities are then identified, as well as a series of proposed next steps to tackle current issues and challenges. Selected papers from the literature are thus reviewed, with a focus on journal papers published between 2010 and 2016. The breakdown of publication years for the reviewed papers is shown in Fig. 1. Figures show that the topic significantly grew in popularity from 2012. It should however be noted that not all published papers were included in this survey, and thi graph does therefore not represent a precise description of the existing literature.

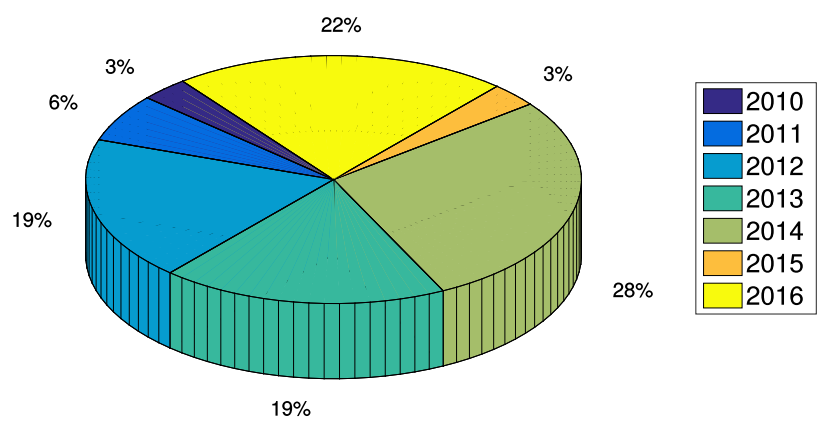

Figure 1: Breakdown of publication years of reviewed studies related to multiple smart homes electric energy management.

The remainder of this paper is organized as follows: section 2 introduces load modeling techniques; section 3 presents the smart home concept and gives a short review of single residential house energy management; section 4 explains the neighborhood concept, introduces the role of neighborhood entities, and reviews studies with a focus on coordination structures and techniques; section 5 presents an overview of the state-of-theart and proposes future steps; and section 6 concludes the paper.

\section{Load modeling techniques}

Designing efficient and reliable HEMS usually requires load models to estimate the impact of control strategies on home energy consumption. In the literature, two main approaches are followed for modeling residential loads: top-down and bottomup approaches. While top-down approaches model each home or the whole residential area as a single unit, bottom-up approaches investigate the energy consumption of each individual load (or group of loads), and aggregate these to obtain the consumption of the whole area or house. A comparison between both approaches is given in Table 1. A comparative review of such models for the residential sector may also be found in [15].

\subsection{Top-down approaches}

The principle of the top-down approach is to aggregate all energy consumption units in one spot (e.g., a home or several ones); thus, only the total energy consumption of a house or a residential area is known [16]. Top-down models often rely on historical data to model the energy consumption of an area, and are typically used to investigate the effect of long term changes (five years or more) on load profiles. The main advantage of this approach is simplicity, as aggregated data is commonly 
Table 1: Residential energy consumption modeling approaches [15].

\begin{tabular}{llll}
\hline & Advantages & Disadvantages & Typical scale \\
\hline Top-down & Simplicity, easy access to data. & $\begin{array}{l}\text { Limited information on individual behav- } \\
\text { iors. }\end{array}$ \\
Bottom-up & $\begin{array}{l}\text { Detailed information on individual behav- } \\
\text { iors. }\end{array}$ & $\begin{array}{l}\text { High model complexity, difficult of data ac- } \\
\text { quisition. }\end{array}$ & $\begin{array}{l}\text { Individual or groups of res- } \\
\text { idences. }\end{array}$ \\
\hline
\end{tabular}

available, for example from distribution transformers. On the other hand, the main drawback of this method is that information about individual peaks, types of loads, load factors and customer behavior are overlooked. As a consequence, precise control strategies cannot be studied, used, or developed with such models.

\subsection{Bottom-up approaches}

Contrary to the top-down approach, the bottom-up approach investigates the energy consumption of each household appliance (or group of appliances) separately. By aggregating the consumption of each appliance, the load curve for a single home or several ones may be easily obtained [17]. Bottom-up models give control system designers the ability to identify areas of potential improvement. However, a drawback of bottom-up models is the difficulty to obtain such detailed data on the consumption of each appliance, as this is typically not readily available in standard homes due to limited instrumentation. Moreover, a validation of the model is required, e.g., by comparing the aggregated load curves with actual measurements from top-down approaches.

Clustering techniques are used with appliances, depending on their working characteristics, usage patterns, end-users preferences, and comfort levels in homes. Household appliances are often divided into three categories, according to their operational characteristics and controllability, although terms may vary: baseline loads (not controllable), burst loads (fully controllable), and regular loads (partially controllable) [18].

Baseline loads, also called non-deferrable loads or must-run appliances, include appliances which are run directly by the customers, and are not controlled by an automated HEMS algorithm. As the usage of such loads is entirely dependent on end-user behaviors, there are no exact operation time intervals for them. As a consequence, models for these loads typically rely on historical load profiles. Lighting, computers, televisions, ovens, music players and other electronic devices are examples of baseline loads.

Burst loads, also called deferrable-shiftable or schedulable loads, have specific operation time intervals with a given energy consumption defined by the technical characteristics of the appliances. These loads can be shifted in time, and may also be paused at specific predefined cycle times. This ability enables significant energy consumption flexibility. For example, a washing machine cycle includes several phases. At the end of each phase, the machine can stop and resume its cycle a few minutes or hours later [19]. Similarly, a clothes dryer usually operates after a washing machines cycle is over. Therefore, the clothes dryer cycle may also be shifted several hours later [20].
Regular loads, also called deferrable-thermal loads, are periodically working appliances with varied operation cycles, and that are affected by environmental conditions. These loads can be interruptible and manageable for short periods of time, depending on end-user preferences. Thermal loads such as electric water heaters, space heating, air conditioning and refrigerators are included in this category [21, 22].

In the residential sector, each end-user has different energy consumption habits depending on behavioral patterns, house occupancy, geographic location, climate conditions, and economics. Therefore, beside the technical characteristics of appliances, historical information about the end-user must also be taken into account while modeling the energy consumption of a house [23].

Grouping household appliances helps in identifying which appliances can be controlled and how long they can be managed over the time horizon. The flexibility of the house demand can then be investigated. Therefore, bottom-up approaches enable understanding the behavior of each appliance as well as each home using statistical analysis. It is thus a requirement to enable the precise control of smart home resources using DR and related techniques.

\section{Energy management in residential buildings}

\subsection{Smart homes}

Over the past few years, classical residential building technologies have evolved to include more advanced features so as to enable the transformation of traditional structures into socalled "smart homes". These homes typically include schedulable appliances, DG, energy storage, EV, a HEMS controller providing access to near real-time information on electricity consumption, weather and changing electricity rates, and enabling technologies such as Internet-of-things (IoT). Fig. 2 depicts a smart home and its components [7].

HEMS are responsible for managing the energy consumption, generation, and storage needs of end-users while meeting their comfort and economic requirements. Communication between the utility and the customer is achieved through AMI and smart meters. AMI provides bi-directional communication between a home area network (HAN) at the bottom-level, and the neighborhood area network (NAN) at the upper level [24]. Using information provided by the utility (e.g., forecast and real-time prices, DR requests) and local information on generation and loads, HEMS attempt to manage energy usage in smart homes by adequately scheduling the use of local and grid resources.

In HANs, the power consumption of the various loads can be measured by "smart plugs" [25], and additional information 


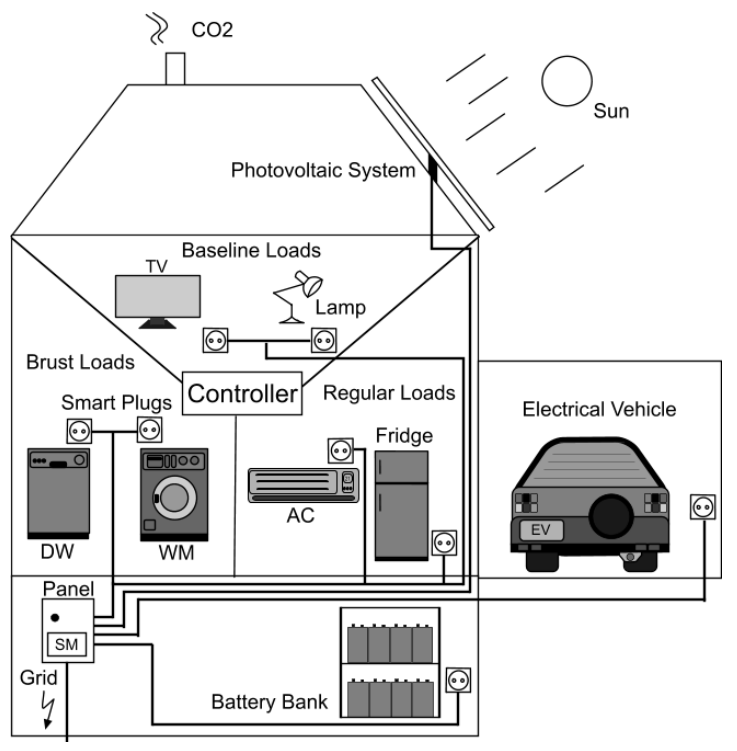

Figure 2: Smart home architecture example (SM: smart meter, DW: dish washer, WM: washing machine, AC: air conditioner).

may be collected by sensors for environmental factors such as temperature and irradiance [26]. The gathered information is typically centralized by the HEMS, through wireline or wireless communication, together with the price signal obtained from the utility. A graphical user interface (GUI), commonly delivered to the user via a computer interface or a smartphone or tablet application, communicates with the HEMS and provides the user with information on current conditions (e.g., consumption, price). Such information is vital for making informed decisions, setting preferences for using smart appliances, or for overriding automatic schedules.

\subsection{Smart home energy management}

Smart homes have been a topic of interest for several decades [27], which only gained significant momentum recently, with the advent of what is now known as the Smart Grid. This has led to publications in both scientific [28] and popular [29, 30] literature, indicating an interest from researchers as well as from the general public.

DSM and DR are activities that affect customer electricity consumption. The terms DSM and DR have relatively close meanings, but are used to address different philosophies. Despite some similarities between both terms, DR's goal is to change end-users' electricity consumption (i.e., the load curve), typically in the range of 1 to 4 hours, in response to an external signal (e.g., price, incentive, etc.) received from the service provider or the utility. On the other hand, DSM focuses on improving the efficiency of electricity consumption in general, in the customer domain [31].

As listed and explained in Table 2, six types of DSM techniques are typically considered [32]: peak clipping or shaving, valley filling, strategic conservation, strategic load growth, load shifting, and flexible load shaping. Peak clipping, strategic conservation and load shifting aim to reduce the load and are the most frequently listed techniques in the literature, as they
Table 2: DSM approaches [33].

\begin{tabular}{|c|c|}
\hline Type & Purpose \\
\hline Peak shaving & $\begin{array}{l}\text { Decreasing peak demand during high } \\
\text { consumption times }\end{array}$ \\
\hline Valley filling & $\begin{array}{l}\text { Deferring demand to lower consumption } \\
\text { hours }\end{array}$ \\
\hline Load shifting & $\begin{array}{l}\text { Decreasing demand during on-peak } \\
\text { hours by shifting loads to off-peak hours }\end{array}$ \\
\hline Strategic conservation & $\begin{array}{l}\text { Reducing the general load profile based } \\
\text { on seasonal changes }\end{array}$ \\
\hline Strategic load growth & $\begin{array}{l}\text { Increasing the general load demand over } \\
\text { the consumption profile }\end{array}$ \\
\hline Flexible load shaping & $\begin{array}{l}\text { Consumption shaping by setting load- } \\
\text { limits at specific hours based on the re- } \\
\text { quirements of the grid }\end{array}$ \\
\hline
\end{tabular}

enable deferring or canceling heavy investments in equipment with higher capacity (such as power lines and transformers).

For example, the flexibility constraint for simple appliance shifting can be formulated as follows:

$$
\left[t_{x}^{\text {orig_s }}, t_{x}^{\text {orig_e }}\right] \in\left[t_{x}^{s c h \_s}, t_{x}^{\text {sch_e }}\right]
$$

where $t_{x}^{\text {orig_s }}$ and $t_{x}^{\text {orig_e }}$ are the initial run start and end times of appliance $x$, and $t_{x}^{s c h_{-} s}$ and $t_{x}^{\text {sch_s }}$ are the acceptable start and end times (i.e., the scheduling window) of the appliance. The scheduling window must be larger than the appliance working duration. As the operation of some appliances may be interdependent, e.g., for washing machines and clothes dryers, additional constraints should be should be considered such as:

$$
t_{w m}^{s c h_{-} s}<t_{c d}^{s c h_{-} s}-\left(t_{w m}^{\text {orig_e }}-t_{w m}^{\text {orig_s }}\right)
$$

where $w m$ and $c d$ indices refer to the washing machine and the clothes dryer, respectively. Such constraints are necessary to enable obtaining realistic schedules.

Such DSM techniques are typically coupled with financial mechanisms (incentives) designed to encourage customer participation. In that regard, two main types of DR mechanisms are widely studied in the literature: incentive-based programs (IBP) and price-based programs (PBP) [34] (Fig. 3). IBP and PBP programs are further subdivided by the Federal Energy Regulatory Commission (FERC) [35]. IBP are classified into six categories depending on their operation modes: direct load control (DLC) [36, 37], interruptible/curtailable (I/C) [38], demand bidding (DB) [39], emergency DR (EDR) [40, 41], capacity market (CM) [42], and ancillary services market (AS) $[43,44]$.

In IBP, the participants receive a financial incentive if they change their consumption according to specifications defined in a contract. DLC and I/C are the most commonly used types, especially for industrial and commercial applications. In DLC, the utility has a remote access to the HAN to directly control some household loads, but for I/C, the utility only offers discounts to customers for a specific electricity reduction amount. In EDR, financial incentives are offered when the system reliability is in danger. In CM, a load reduction is committed before the occurrence of the critical conditions. In DB, consumers bid 
for load reduction at a given price, and if their bid is cleared, consumers decrease their load consumption, otherwise they are penalized. Lastly, in AS, as in DB, consumers bid a load reduction amount on the ancillary services market. If their bid is accepted, they perform the curtailment and receive the market price as a compensation [46, 47]. However, direct participation in markets is not always possible due to minimal capacity requirements.

In PBP, the utility indirectly affects the electricity consumption of the consumers using time-varying pricing mechanisms, usually in order to reduce the peak-to-average ratio (PAR) of the electricity demand. In other words, the time-varying pricing mechanisms are designed to modify the behavior of the customer, thus affecting the consumption pattern. For example, a higher price provides an incentive for customers to reduce their consumption, thus the customer is able to change the amount and time of electric energy usage depending on preferences. Various pricing mechanisms, such as time-of-use pricing (TOU), real-time pricing (RTP), and critical peak pricing (CPP), are used by utilities to encourage customers to actively participate in PBP $[6,48]$.

- $T O U$ is a pricing mechanism in which different rates are used depending on the time of the day. Several blocks of hours during the day are defined as off-peak, average load and on-peak periods. The rate is designed to be higher during the on-peak periods, and lower during the off-peak periods. For example, the Ontario province in Canada uses TOU with off-peak, mid-peak and on-peak periods [49].

- RTP has dynamic rates that change for every hour of the day. The forecasts of these rates are given a day or an hour in advance by the utility company to the end-users [50]. RTP is more fluctuating than TOU and better reflects the real-time balance between generation and demand. However, it can also be more difficult for end-users to schedule their consumption due to the frequent rate fluctuations. ComEd's hourly pricing program is an example of RTP scheme [51].

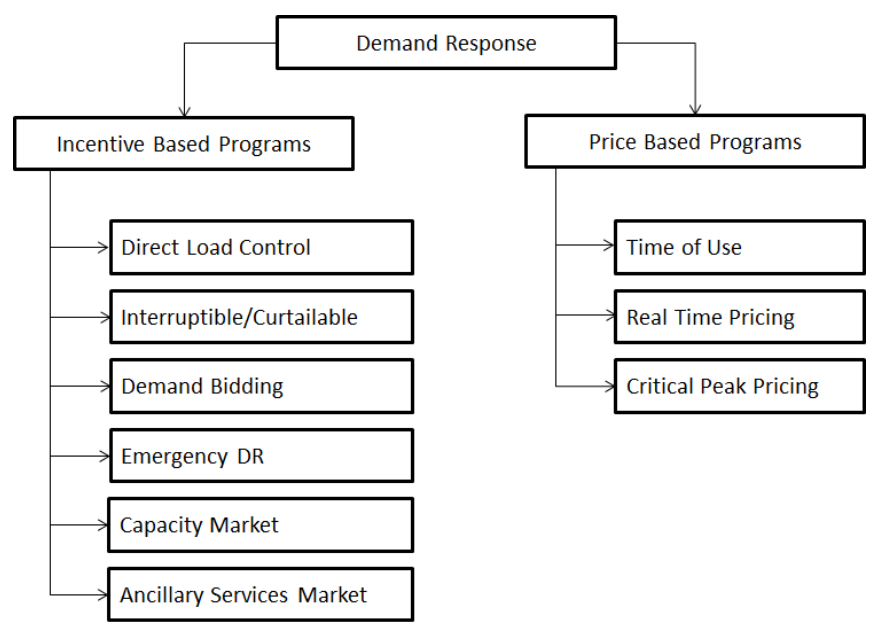

Figure 3: Demand response programs [45].
- $C P P$ is a pricing mechanism that is sometimes used in addition to TOU in order to present higher charges to the end-user during times when operating conditions are critical, such as during contingencies, and is therefore only used a few times a year. For example, in California, SDGE uses a CPP scheme [52].

DR programs are therefore a key concept not only to reduce the electricity bill, but also to decrease $\mathrm{CO}_{2}$ emissions by reducing the need for polluting peaking power plants. As a consequence, DR provides benefits for both the customers and the utility. On the customer side, end-users can change their consumption patterns by modifying their consumption habits so that their electricity expenses are reduced. On the utility side, by reducing the peak-to-average ratio (PAR) of electricity demand, DR programs can reduce the stress of operation on grid assets, decreases outage risk, provide efficient utilization of the RES, and secure grid reliability and stability [53]. At the same time, DR benefits to society as a whole, by helping reduce market price spikes as well as harmful greenhouse gases emissions from fossil fuel-based power plants. Although this paper focuses primarily on academic works, multiple demonstrations and pilot programs $[54,55]$ have shown that such approaches are valid, but also have specific limits, as further discussed in Section 5 .

Table 3: Classification of the selected reviewed DR studies. Incentive-based DR [34], [56], [57]

Price-based DR [58], [59], [60], [61], [62], [63], [64], [65]

\subsubsection{Incentive-based single home energy management}

The following paragraphs review selected IBP methods, with a focus on single home electric energy management. The selected papers are listed in Table 3. In [56], a load commitment formulation is extended with a DLC program to control responsive loads in emergency conditions (e.g., the loss of a large generator or transmission line), and to provide lower electricity costs and PAR values through appliance scheduling. The gained profit is related to consumer comfort, and is determined by the electricity cost reduction. When the household consumption is decreased in the emergency condition, the electricity tariff decreases. Compared to the base case, when the consumer neglects its comfort, a cost reduction is obtained for the simulation duration. However if the consumer gives priority to its comfort, the total cost slightly increases.

In [34], the HEMS problem is formulated as a mixed integer nonlinear program (MINLP) with an inconvenience factor that corresponds to the difference between the baseline and optimal results. An incentive reward for power reduction during peak hours is considered. The MILP program schedules 10 controllable appliances with operation time limits and power rates as defined by the customer. Incentives are defined for early morning and after working hours. Compared to the reference scenario, customers can save up to $25 \%$ in electricity costs. 
In [57], incentive rewards are used with battery and PV management for controlling household area consumption. The used method takes into account the stochastic behavior of price, water usage, PV generation and loads. Incentive rewards are offered based on the participation of the consumer to the DR event. Results show that DR can decrease the customer electricity bill by $18 \%$.

The above studies show that using IBP, in critical conditions, the utility can satisfy grid security requirements and consumers can reduce their electricity bill. However, consumers cannot benefit for frequent cost reductions, as they depend on utilities for receiving incentives. Moreover, if a consumer accepts the IBP contract and does not participate in the program when the request from the utility is received, he/she is penalized by the utility. Also, if DR requests are too frequent and his/her comfort is impacted more often than expected, the customer may decide to opt-out of the program. Another difficulty lies in determining the baseline load profile for the end-user, so his/her financial compensation can be determined. While there is little difficulty in achieving this for selected types of industrial and commercial users, it may be more complex for residential ones due to the limited number of small loads running.

\subsubsection{Price-based single home energy management}

As for IBP, a short review of selected PBP methods is proposed. The selected papers are listed in Table 3. In [58], TOU is used to minimize the electricity bill of consumers while taking into account end-user preferences and managing overload conditions. User preferences include the acceptable time intervals for appliances to run. TOU is used in three simulation scenarios, each with a different objective: (a) avoiding overload, b) optimizing savings, and c) participating in a DR program. Simulation results show that all strategies achieve their expected goal; however, although b) can include a), c) considers different constraints and cannot be directly compared with others.

In [59], a decision-support tool with forecasting and scheduling capabilities is developed. An adaptive neural fuzzy inference system (ANFIS) is used for forecasting the expected electricity demand, then a branch-and-bound method is used for appliance scheduling. This study takes into account TOU tariffs with power availability at specific time intervals and consumer comfort. Results show a reduction in the total cost of deferrable appliances electricity cost from $\$ 0.19$ to $\$ 0.14$, for the simulation duration.

In [60], a performance comparison is presented for different HEM applications for consumer benefit. The impact of TOU, RTP, and priority-based scheduling are compared. Simulations are performed for 210 days. Cost reductions are determined for several scenarios: $30 \%$ with TOU, $45 \%$ with TOU and PV with a feed-in-tariff, $27 \%$ without the feed-in-tariff, $9 \%$ with priority-based scheduling, and $18 \%$ with an RTP program.

In [61], scenario-based stochastic and robust optimization algorithms are presented to schedule household appliances using 5-minute intervals with RTP pricing. The presented methods also take into account RTP uncertainties while minimizing operation costs. Both optimization methods are compared in terms of performance and computation time. Results show that while stochastic optimization achieves $26.6 \%$ cost reduction, robust optimization exhibits lower performance with $24.3 \%$ reduction. However, the computation time for robust optimization is shorter than for stochastic optimization.

In [62], a HEM strategy is presented to reduce the cost of consumed energy under RTP tariff by scheduling resources and PV and battery operations. It uses a framework called Action Dependent Heuristic Dynamic Programming (ADHDP) that relies on neural networks. An online and an offline particle swarm optimization (PSO) algorithm are used to determine the optimal schedule, as well as for pre-training the networks and improve algorithm performance. While the online PSO algorithm works only in the current time period, the offline PSO algorithm also uses data on forecast RES generation, load and prices near the current state. Results are compared in four different cities. Depending on the considered city, savings can reach $9.3 \%$, with ADHDP with offline PSO pre-training returning the best results.

In [63] and [64], authors combined the RTP tariff with incremental block rates (IBR). IBR is a pricing scheme where the unit price increases with the amount of electricity consumption, i.e., the higher the consumption, the higher the unit price. In [63], two approaches are considered for HEM design: deterministic and stochastic. The stochastic approach considers uncertainties in appliance operation time and consumed energy through an energy adaptation variable $\beta$, while the deterministic approach, based on linear programming, does not. A total load consumption limit is defined for the smart home, so that excess loads are tripped. Compared to the baseline case, results show that to the total cost can be reduced by up to $41 \%$.

In [64], the authors combine RTP with IBR and compare full and partial flexibility in load scheduling. In the full flexibility approach, individuals only focus on profit (or savings) and preferences are not considered, while for the partial flexibility approach, customer preferences are also taken into account in the scheduling process. Both are formulated as mixed integer linear optimization problems. Results show that end-user costs decrease on average by about $20 \%$ when the schedule is partially flexible.

In [65], an HEMS is developed with a two-horizon algorithm (THA) and a rolling-horizon technique. Goals are to increase computational efficiency compared to traditional moving-window algorithms, and to achieve load management with TOU, RTP and a predefined peak demand charge (PDC) paid for electricity bought during peak periods. The algorithm uses two time horizons: one is for short-term scheduling with a high time resolution (THA-s) and the other is for longer term scheduling with a lower resolution (THA-1). THA-s is combined with THA-1 in the rolling horizon technique to reduce the computational burden of the energy management algorithm. The study shows that the proposed THA algorithm returns $18 \%$ better results with RTP than with TOU for a one-week simulation. Results show that when the PDC price increases, the THA algorithm achieves more cost reduction.

Through time-varying price signals, the utility or the aggregator provides opportunities for consumers to reduce their bills. Consumers, on the other hand, try to find the right balance be- 
tween the induced loss of comfort and the financial gains from the DR program. Overall, PBP can be expected to provide more frequent cost reduction opportunities compared to IBP, as they are not necessarily linked with grid condition. However, PBP approaches introduce some uncertainty for the utility, as the achieved load reduction amount depends on end-user response to prices. Moreover, due to their frequent and hard to predict variations, schemes such as RTP are difficult for end-users to adapt to, and may be rejected.

\section{Neighborhood energy management}

In the previous sections, the proposed methodologies ignored the energy consumption of other households while controlling their own loads. Such myopic HEM strategies may potentially lose the benefits of a global optimum in energy management goals. In typical DR programs, all customers receive the same signal from the utility, thus posing a potentially significant risk that they may all shift their appliances to run during the same hours $[66,67]$. In this case, although the objective of the DR program was to reduce demand during high price periods, an unexpected peak demand called "rebound peak" may occur immediately after the DR event has ended. This effect may lead to an even higher demand peak that the DR program tried to avoid in the first place and that may in turn threaten grid stability $[13,68]$. For this reason, from the perspective of the utility, such narrowly focused individual customer-side optimization can reduce the effectiveness of DR programs [69]. Coordination mechanisms are therefore required for neighborhood energy management.

In this section, the concept of neighborhood-level coordination is introduced. The communication and control structures, the roles of entities (utility, aggregators, and end-users), and the coordination mechanisms used in the literature are described with their respective underlying theories.

\subsection{Concept of neighborhood area}

Smart neighborhoods rely on individual smart homes, that are interconnected through an electricity and a communication network. These networks enable a variety of mechanisms for managing energy at the neighborhood level.

\subsubsection{Neighborhood area structure}

A neighborhood area may be defined as a group of houses located in the same geographical area. Its size may range from a few houses to possibly a few hundreds. The location of the neighborhood area in the general electricity structure is given in Fig. 4.

Similarly to a HAN, a neighborhood area network (NAN) enables smart homes (each with its own HAN) to communicate and coordinate their actions. The NAN is formed by a collection of smart homes equipped with smart meters to collect consumption and generation data from resources (DG, storage devices, loads). Each meter has two-way communication ability in the NAN. Information is usually aggregated at the feeder or substation level by a concentrator or gateway [70]. This concentrator can then communicate with the utility information system or the aggregators.

Aggregators are new entities that, as the name implies, aggregate energy or power from small scale consumers and try to sell this aggregated capacity on markets. Aggregators typically aggregate load reduction capacity from many customers and sell it on markets, hence generating revenue for the participating customers [71, 72].

Depending on the size of the area and local legislation, none, one or multiple aggregators may be available [73, 74]. An aggregator may not be required if the local utility communicates directly with each home. However, for large regions serving hundreds of thousands of customers, the number of controllable assets increases dramatically and aggregators can facilitate the coordination of these resources. Aggregators can thus act as intermediaries between the utility and customers for specific needs. In a restructured market, multiple aggregators may be competing with each other, and also potentially with suppliers.

\subsubsection{Role of electricity entities}

In this subsection, the roles of the various entities depicted in Fig. 4 are reviewed.

- Utility operator: At the top level, the utility has to ensure reliable electricity delivery energy to end-users. As issues such as T\&D congestion may occur, DG and DR programs may be useful for the utility to increase local generation or decrease load. The utility can communicate with aggregators and possibly customers to coordinate their actions, e.g., for DR.

- Aggregator: At the middle level, aggregators have three roles depending on operation conditions: a) The aggregator negotiates with end-users (customers) in the neighborhood to provide DR services to the utility. In this condition, from the end-user perspective, the aggregator temporarily undertakes part of the role of the utility operator, and influences electricity consumption patterns through price/energy-volume signals in the retail market; b) The aggregator receives ancillary service requests from the utility operator to secure the system; c) The aggregator acts as an independent entity and tries to profit from electricity trade, by selling negative load on markets [14].

- End-users: With the increase in penetration of DG and storage devices, end-users can also play several roles [75]. Depending on the electricity balance between household electricity components (e.g., loads, DG, storage units, and $\mathrm{EV}$ ), end-users are alternatively taking the role of consumer or producer from the perspective of the aggregator.

This structure provides a basic infrastructure for electricity and information flow, that coordination algorithms use to achieve their objectives. 


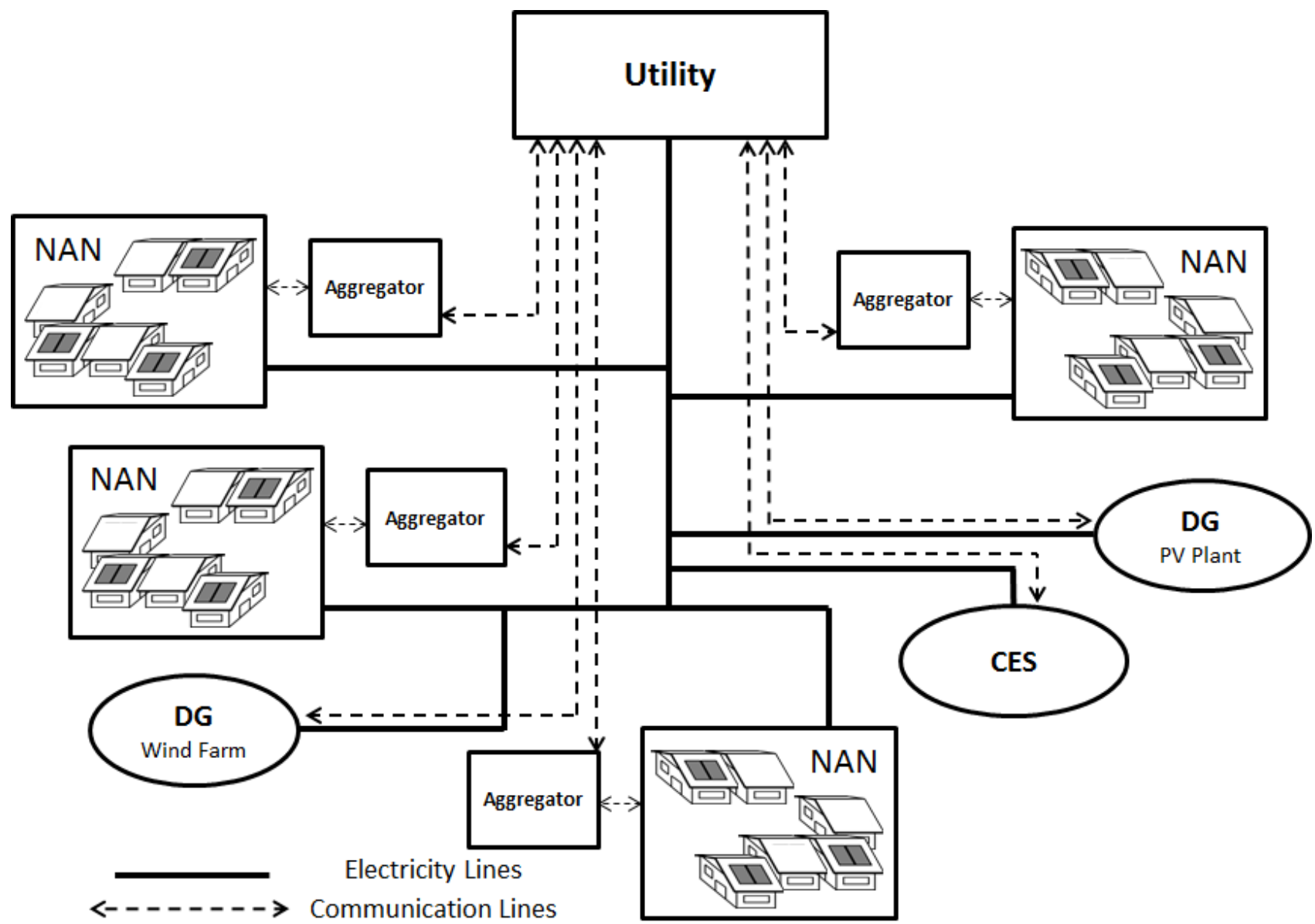

Figure 4: Electricity network structure example (CES: community energy storage).

\subsection{Coordination structure and objectives}

In this section, two coordination structures, namely centralized and decentralized, are distinguished, depending on the used communication and control architectures. The reviewed papers are listed in Table 4.

Table 4: Classification of the selected reviewed studies with respect to coordination structures.

\begin{tabular}{lll}
\hline \multirow{2}{*}{ Centralized } & & {$[14],[76],[77],[78],[79]$,} \\
& & {$[80],[81],[82],[83]$} \\
\hline \multirow{3}{*}{ Decentralized } & Fully-depend. & {$[66],[84],[85],[86],[87]$,} \\
& Fully-independ. & {$[88],[89]$} \\
& Partially-independ. & {$[68],[91],[92]$} \\
\hline
\end{tabular}

\subsubsection{Centralized coordination}

In this framework, as shown in Fig. 5, there is one central operator, which can be the utility or an aggregator. This central operator manages (a part of) the electricity usage of all smart homes. It has direct access to all information on end-users' household electricity appliances through secure AMI networks.
Smart meters and HEMS send information about their electricity usage and preferences to the central operator. The operator then optimizes electricity consumption by scheduling appliances operation for each household. The decisions taken by the central operator are then sent to smart homes and the strategy is applied.

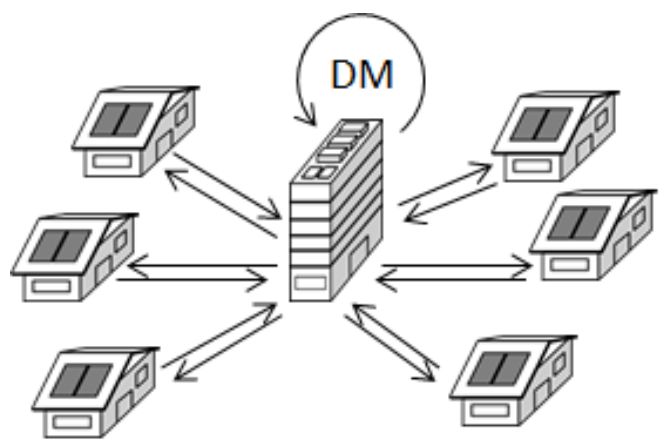

Figure 5: Principle of centralized coordination (DM: decision making).

In the following, selected papers that use centralized coordination schemes are reviewed. In [76], a day-ahead DSM strategy coordinated by a central operator is proposed for a large 
residential area including 2600 smart appliances. The goal is to minimize electricity consumption while reducing the PAR of the demand profile. To obtain the desired load consumption, the proposed DSM algorithm uses load shifting to bring the actual load curve as close as possible to an objective (target) load curve derived from the objective of the DSM strategy, i.e., to minimize costs. The proposed DSM method achieves a $5.0 \%$ cost reduction, and a $18.3 \%$ peak load reduction for the area.

In [77], three centralized control algorithms are proposed for demand management in a neighborhood area. The main purpose of the presented algorithms is to decrease electricity consumption during on-peak hours by controlling refrigerators. The first proposed algorithm is a synchronous model in which a central controller sends on/off signals to all refrigerators in the area at the same time. Secondly, an asynchronous algorithm is proposed to trigger on/off signals at different times. Thirdly, a dynamic temperature interval management algorithm is proposed. In the latter method, the lowest and highest temperature points are sent rather than the on/off signals. Results show that while the synchronous model is effective to decrease peak load (close to zero), it also leads to a significant rebound peak. The asynchronous model results in a lower rebound peak but only achieves a $21.4 \%$ peak load reduction. The last strategy seems to provide the best results, with a peak load reduction of up to $41.5 \%$ and a negligible rebound peak.

In [78], a joint optimization algorithm for EV charging and HVAC control is proposed. The goal is to minimize the total electricity cost for the residential community while considering user preferences. In the neighborhood, parked EV may also charge other EV and provide electricity to HVAC units, in order to minimize electricity imports from the utility. Here, the aggregator collects information about the EV and HVAC units, such as thermal dynamics, user climate comfort preferences, battery state, user travel patterns, and household occupancy. The community scale optimization result is compared with individual optimization for 100 households. According to results, the proposed algorithm manages to reduce the aggregated electricity cost by $22.8 \%$ for a hot summer day.

In [79], a centralized scheduling algorithm is proposed to minimize electricity imports from the main grid by allocating the loads and EV charging to periods when RES generation is high. A feed-in tariff program is presented that favors the discharge of EV to supply other household appliances in the grid. Three simulation results for centralized optimization are compared: naive (base case), optimal without EV discharge, and optimal with EV discharge. Compared to the base case, the optimal case without EV discharge returns a $4.3 \%$ cost reduction for $10 \mathrm{EV}$ and around $75 \%$ for $400 \mathrm{EV}$, and the case with $\mathrm{EV}$ discharge returns a $8.5 \%$ cost reduction for $10 \mathrm{EV}$ and $175 \%$ for $400 \mathrm{EV}$.

In [80], a real-time load management and optimal power generation algorithm is presented for an islanded grid. A central coordinator is responsible for the cost and capacity limit of a backup generator, RES, and storage devices. Each household informs the central operator about the electricity consumption of its appliances, then the operator responds with an optimal scheduling strategy that considers the capacity limits of gener- ation and storage units. Two algorithms are proposed: an offline algorithm that relies on forecasts, and an online algorithm that handles disturbances in real-time. Based on simulation results, the offline control method reduces the total electricity cost from $\$ 11.12$ to $\$ 8.03$ for the simulation duration, when disturbances are neglected. On the other hand, the online scheduler, when the uncertainty on solar generation and appliance operation are considered, reduces the total electricity cost from $\$ 10.8$ to $\$ 7.80$.

In [14], an aggregator-based control approach for DR is proposed. The aggregator tries of maximize its profit by selling on markets the capacity aggregated from customer smart appliances. Each customer can choose in real-time between buying electricity from the aggregator (at a price called customer incentive price) or from the utility (at the real-time price). The aggregator gathers settings from end-users and computes optimal set points using a genetic algorithm for 5,555 households, i.e., 56,642 appliances. The algorithm also computes the optimal customer incentive price that enables the aggregator to Results show that customers can save from $\$ 0.02$ to $\$ 0.33$, while the aggregator generates a profit of \$947.9.

Several other studies using centralized coordination focus on specific aspects. For example, in [81], authors propose an algorithm capable of allocating a fair share of distribution transformer capacity among users. In [82], a centralized and a decentralized approach are compared in terms of optimization performance and computation time for the energy trading problem among smart homes. Finally, [83] uses model predictive control for the centralized coordination of smart buildings and considers the stochasticity of renewable energy sources and loads.

Overall, studies show that centralized approaches enable finding the optimal strategy for efficient electric energy use, as well as for maximizing the utilization of DG. A drawback is however the computation burden required by the optimization, especially for a large number of assets to control [14]. Centralized control is thus not suitable for large-scale applications where computation time would become prohibitive. Nevertheless, results from centralized coordination can be used as a reference for comparison with other coordination methods [93].

\subsubsection{Decentralized coordination}

While in centralized coordination, the central operator has access to information about all consumers, in decentralized coordination, the end-users schedule their assets directly, without any omniscient central entity. To achieve this, smart homes have to communicate with each other or with a central entity to gather sufficient information about the neighborhood electricity profile. Depending on the communication structure in the neighborhood and the level of decentralization, three approaches are distinguished: fully-independent, partially-independent and fully-dependent (Fig. 6):

- In the fully-dependent structure (Fig. 6a), smart homes receive information on the neighborhood electricity profile through a central entity without sharing any data with each other. Neighborhood communication is dependent on the 
central entity. The difference with centralized coordination is that the decisions are taken by the smart homes, and not by the central entity.

- In the fully-independent structure (Fig. 6b), smart homes communicate with each other in the neighborhood, without any central entity. They are able to communicate with each other directly, and share data on the neighborhood load profile.

- In the partially-independent structure (Fig. 6c), smart homes communicate with each other, and also interact with a central entity.

In the following, selected papers that use a decentralized coordination structure are reviewed. In [66], the rebound peak issue due to uncoordinated load shifting of appliances to off-peak hours is addressed. To solve it, a fully-dependent optimization algorithm is used to coordinate electricity consumption in the neighborhood. As the same DR program - triggered by the same price signal-is used in all smart homes, all controllable appliances in the area are shifted to the same off-peak hours, which may cause another peak. To avoid the resulting rebound peak effect, four techniques are compared, each with different DR and price signals: random DR scheduling without and with flattening, different prices for different homes (although the legal feasibility of this approach is questionable), and maximum power constraint. Compared to a base case, the various techniques return peak and cost reductions ranging from $19.4 \%$ to $33.9 \%$, with the last technique providing the best results.

In [84], a fully-dependent decentralized energy management algorithm is proposed. The proposed greedy algorithm tries to minimize electricity bills by optimizing the start time and operation mode of appliances in smart homes. The cost of electricity is modeled by a time-dependent unit retail price, which means that the electricity price changes with the aggregated consumption in the neighborhood. To determine the price, the utility receives information on the consumption of each individual house, and sends a price signal to each consumer. Depending on the price, consumers schedule their controllable appliances to decrease their expenses. Then, depending on the scheduled consumption, the utility aggregates the total load again and determines the new electricity price. After that, consumers, depending on the new price, schedule their appliances agin. This process continues until the difference between consecutive decisions becomes negligible. Results show that individual users are able to reach cost reductions of about $20 \%$, and that results for the proposed distributed method are close to the ones obtained using classical sequential optimization.

In [85], a fully-dependent energy management algorithm is presented to decrease the total electricity cost of a neighborhood. The neighborhood area includes a central operator called load serving entity (LSE) and multiple households with RES, storage devices, and controllable and non-controllable loads. Each household, depending on information received from the LSE, solves an optimization problem to minimize its electricity bill using an approach called Lyapunov-based cost minimization. After the LSE has received the consumption informa-
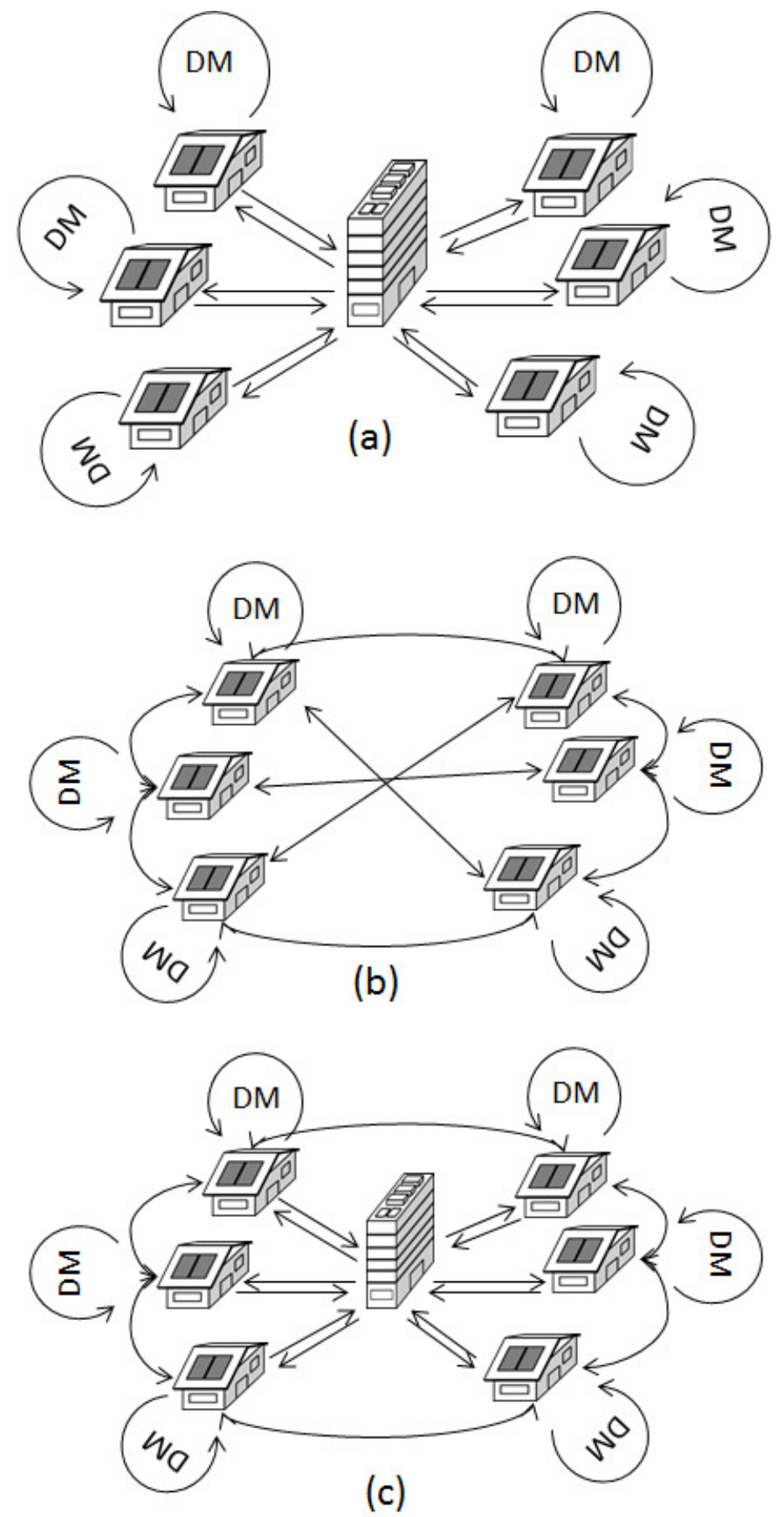

Figure 6: Principle of decentralized coordination: (a) fully-dependent, (b) fullyindependent, (c) partially-independent (DM: decision making).

tion from each household, it determines the electricity price for the defined period, and each household solves the optimization problem again with the new price. This process continues until convergence is obtained. In the results, the proposed algorithm is compared with two other cases: no storage and no DR (case 1 ), and with storage and no DR (case 2). Over a six month period, the presented control method reduces electricity costs by $20 \%$ and $13 \%$ compared to cases 1 and 2 , respectively. 
In [86], a fully-dependent two-level load control strategy is proposed to address the rebound peak issue. The proposed method does not rely on a specific electricity pricing scheme, hence customers are free to select the scheme (flat, TOU or RTP) of their choice. To eliminate the rebound peak and minimize costs at the same time, two different optimization algorithms are defined. First, homes receive the electricity price, optimize their assets schedule, and send the results to the service provider. This service provider then calculates the aggregated profile and sends it with a desired (flatter) aggregated profile back to the customers. As a second step, customers optimize their profile again to flatten the area profile and try not to jeopardize their previous cost results. Compared to noncoordinated control (i.e., with only the first step), the proposed method achieves a $16.8 \%$ additional peak load reduction.

In [90], two fully-independent selfish DSM algorithms are presented. The neighborhood is modeled as a graph, and close neighbors exchange messages with each other. These messages enable two coordination mechanisms: synchronous agreementbased, and asynchronous gossip-based mechanisms. In the synchronous agreement-based algorithm, consumers estimate and share the predicted aggregated consumption at the same time using information on their own consumption. The coordination process ends when consumers agree on the aggregated consumption of the neighborhood. In the asynchronous gossipbased algorithm, consumers update their knowledge of the aggregated consumption at different times. The electricity cost and the PAR value are reduced by $33.34 \%$ and $30.31 \%$, respectively, with the proposed DSM programs. Although both algorithms return similar results, the gossip-based algorithm requires more iterations due to the asynchronous nature of the communication.

In [91], a partially-independent, selfish scheduling algorithm based on game theory is presented for the purpose of minimizing the PAR of the load profile. A central operator sends price information to the end-users, who have the ability to exchange data about their demand power. For each iteration, if the consumer changes his/her last decision, he/she needs to inform others. Scheduling is then performed while considering temporally-coupled constraints. For example, an EV should be fully charged by the time the driver expects to leave home, hence the scheduler can only shift the corresponding asset schedule to a certain limit to enable a full charge. In results, the PAR of three customers are reduced from 2.6, 2.7, and 2.4, to $2.1,2.2$ and 2.0, respectively. The scalability of the algorithm is also investigated, and results show that the approach could be scaled to real-world problems.

In [92], a partially-independent coordination structure aims to minimize the electricity bills of the end-users while taking into account the aggregated neighborhood consumption. Endusers participate in a scheduling game to reduce their electricity bill, as well as the PAR of the neighborhood demand. The electricity provider determines the electricity price according to the aggregated consumption profile. End-users are charged based on the ratio of their individual consumption over the aggregated consumption. As a result, the aggregated electricity cost of the residential area is reduced from $\$ 44.77$ to $\$ 37.90$ for the simu-
Table 5: Classification of the selected reviewed studies with respect to coordination techniques.

\begin{tabular}{ll}
\hline Multi-agent systems & {$[94],[95],[96],[97]$} \\
Game theory & {$[98],[99],[100]$} \\
Optimization techniques & {$[85],[101],[102],[103],[104],[105]$} \\
\hline
\end{tabular}

lation duration, and the PAR is decreased from 2.1 to 1.8 .

In [68], a partially-independent collaborative energy management algorithm is presented to reduce the real-time power balancing electricity cost of the neighborhood. While consumers are connected to an aggregator or retailer, they coordinate their actions by exchanging messages with each other. In the presented study, the retailer pays a price higher than the real-time electricity market price, which is different from the wholesale day-ahead electricity market due to uncertainties in demand. The proposed algorithm focuses on the minimization of the total cost in the real-time electricity market. It is compared with selfish scheduling, which causes a rebound peak in the aggregated consumption profile, while the proposed approach does not. Cooperative scheduling also returns the lowest aggregated deviation compared with cases without scheduling and with selfish scheduling.

Additional papers introduce interesting methods based on a decentralized approach. In [87], decentralized coordination is achieved with a two-level optimization in which customers optimize their utility function and the aggregator determines the lower and upper bounds of the consumption of each customer. In [88], a detailed mathematical model is presented for decomposing the centralized optimization problem into a set of independent decentralized problems. Finally, in [89], energy trading between smart homes with PV and centralized energy storage and the grid is studied using a decentralized game theoretic approach.

Overall, the reviewed papers show that decentralized coordination leaves more freedom of choice to the end-users; however the aggregated cost is usually higher than for centralized coordination. On the other hand, some individual homes may be gaining more than others, e.g., when they have more flexibility. As this approach requires frequent communication and sometimes a large number of iterations to converge, a drawback is that the necessary bandwidth and the convergence time may be significant.

\subsection{Coordination techniques}

This section focuses on how houses cooperate, compete, or coordinate their actions to achieve certain pre-determined goals. Three main approaches are discussed: a) multi-agent systems (MAS); b) game theory (GT); and c) optimization techniques. The reviewed papers are listed in Table 5.

\subsubsection{Multi-agent systems (MAS)}

MAS are widely studied and used various fields, ranging from economics to computer science, mainly due to their suitability for distributed problem solving [106]. Over the last few years, especially as a consequence of the rapid penetration of 
DG installations in the distribution grid and the associated need for decentralized control, MAS have become a technique of interest to power control engineers [107, 108]. Applications range from building energy management [109] to microgrids [110], distribution systems [67] and power plants [111].

According to [112], an "agent is a software or hardware entity that is situated in some environment and is able to autonomously react to changes in that environment." In this definition, autonomy means that each agent can make its own decisions in order to attain its objectives. The environment corresponds to everything surrounding the agent, except itself. According to [107], agents have three main properties: i) reactivity: the ability of an agent to react to changes in its environment; ii) proactivity: the ability of an agent to proactively behave according to its defined objectives; and iii) social ability: the ability of an agent to negotiate (compete or cooperate) with other agents.

A MAS is a group of agents with the ability to communicate with each other to cooperate or compete for achieving their objectives in a changing environment. Under the scope of this paper (coordination of multiple houses), agents are usually the controllers of the HAN in the smart homes. They meter and control the household appliances; additionally, they also communicate with other HAN and NAN agents in the neighborhood. Through such communication, they can observe the grid condition and act on it if required (reactivity), cooperate (social ability) to ensure the reliability of the system (proactivity) or compete (social ability) with each other to minimize their electricity bills (proactivity). As a consequence, while MAS may not be considered as an algorithm, they are an enabler for decentralized coordination techniques.

The organizational structure is an important characteristic of a MAS and includes the following types: hierarchies (the most commonly used for power system applications), holarchies, coalitions, teams, congregations, societies, federations and marketplaces [108].

In a hierarchical MAS, the electricity network is divided into several levels, typically three. Agents are categorized in these levels depending on their duties or objectives [113]. The upper level is the system control level that decides about operation strategies and operation modes. The middle level is the central control level with tasks including energy generation and consumption forecasting, voltage and frequency control, supplydemand matching, and day-ahead optimum DG scheduling operations. The bottom level is the local control level for coordinating local resources. Three types of agents are typically defined at the bottom level, such as a) $D G$ agent: responsible for controlling (whenever possible) the output of a DG; b) storage agent: responsible for the charge and discharge operation of a storage device; c) household agent: responsible for organizing the schedules and shedding operations of appliances (including PV units) with the objective of minimizing electricity bills while ensuring a minimum impact on consumer comfort. With the development of transportation electrification, EV may also be modeled as agents for charging (home-to-vehicle: H2V) and discharging (vehicle-to-home: V2H) [94].

In [95], a MAS-based DSM algorithm is proposed for an is- landed grid with multiple sources. A four layer structure is used for modeling the network, with: a) a prediction layer, b) an activation layer, c) an intelligent supervisory layer, and d) a control layer. Prediction layer agents estimate the future electricity generation from PV panels and wind turbines. Activation layer agents use frequency control to decide whether or not to activate load shedding depending on the frequency fluctuations. The activation layer agents use the prediction information received from the prediction layer agents and storage information received from the control layer agents (e.g., fuel cell agent, desalination unit agent, and electrolyzer agent). In the intelligent supervisory layer, the supervisor agents of the households negotiate with each other to decide whether to turn-on or off household appliances, after receiving the control signal from the activation layer. In the control layer, control agents are responsible for controlling home appliances. Simulation results show that shedding is activated for a total of 62 hours in summer.

In [96], electricity trading inside and outside of a neighborhood is studied. Consumers are modeled as agents and decide about selling, buying, or storing electricity. To take decisions, consumer agents communicate with each other and take decisions on their actions using a rule-based algorithm. For example, the agents can decide whether to store excess energy or sell it inside the neighborhood (first priority), or to sell it to the utility (second priority). After scheduling their appliances, agents can then choose to buy either from the utility or from inside the neighborhood. To minimize electricity bills, consumers thus have four options: load shifting, purchasing electricity from the neighborhood, battery charge or discharge, and selling excess energy to the grid or the neighborhood. Results show that customers could benefit from diversity in end-user types, in the form of increased savings (up to 10\%). Depending on the assumed penetration rate of PV and battery units, end-users could also expect to save up to $40 \%$ on their electricity bill.

In [97], DR and DG management are combined to study the overloading issue in islanded grids while taking into account plug-in hybrid vehicles (PHEV). In the proposed study, a threelevel hierarchical MAS structure is used. From top to bottom: grid agents control grid resources (battery, wind turbine and DG), control agents communicate with the grid and resident agents for satisfying the balance between generation and consumption, and resident agents collect information on demand and PHEV battery state-of-charge. Control actions are determined by defining a critical peak price in the microgrid to shed low priority loads, reduce electricity consumption, and decide about the charging modes of the PHEV. Three cases are presented and compared with each other. Results show that the peak load in the studied system can be reduced from 900 to 800 $\mathrm{kW}$, i.e., by $11 \%$.

The above reviewed studies show that a MAS advantage is the possibility to have a decentralized intelligence, with numerous homes modeled after a single template agent while all can have different characteristics (e.g., appliance count and preferred operation time). Agents can also automatically adapt themselves to environmental changes such as changes in the structure of the neighborhood (e.g., a new home), without requiring any major interruption and changes in the algorithm. 
Drawbacks include the costs of such approaches, that result from a larger number of communicating entities. Additionally, few standards (e.g., IoT standards) currently exist, which makes development longer and costlier.

\subsubsection{Game theory}

GT is a strategic decision-making process, originally developed by J. von Neumann and O. Morgenstern [115]. GT is the science of strategy that determines the relationship and interactions between players, and analyses their behaviors under some given circumstances, called games. In these games, players choose the best strategy as an action to achieve the best outcome by anticipating the strategy of other players. Although GT is mostly used in economics [116, 117], it has also been widely applied to other fields such as computer science [118, 119] and electrical engineering [120].

According to the previous definition, GT may be applied to power systems with the following adaptations: a) participants (typically, end-users) are defined as rational and strategic decision-makers [121]; b) players select the best strategy they can by anticipating the actions of other players [122]; c) consumers make their own decisions through decentralized problem solving [92, 123].

Games consist of three components (player, strategy and payoff function), and are usually noted $G=\{N,\{S\},\{U\}\}$. $N$ represents the households set. $S$ represents the strategy space of the game, hence $S_{i}=\left\{s_{i, 1}, s_{i, 2}, s_{i, 3}, \ldots, s_{i, \omega}\right\}$ is the set of strategies (generally, the consumption for the home) for home $i$. $U$ represents the set of payoff functions (electricity costs or savings). A Nash equilibrium is reached when the following condition is met:

$$
U_{i}\left(S_{i}^{*}, S_{-i}^{*}\right) \geq U_{i}\left(S_{i}, S_{-i}^{*}\right)
$$

$S_{i}^{*}$ is the strategy of house $i$ at the Nash Equilibrium, and $S_{-i}^{*}$ is the strategy of other players, also at the Nash Equilibrium. $S_{i}$ represent the deviant strategy of player $i$, i.e., a strategy that does not lead to a Nash equilibrium. In other words, a Nash equilibrium represents a balanced state where players can no longer improve their payoff by changing their optimal strategy when considering others' strategies as fixed [99, 124]. The outline of a Nash equilibrium game algorithm for multiple smart homes with one aggregator is described in Algorithm 1.

In the following, selected studies from the literature employing GT are reviewed. In [98], a scheduling game is formulated to reduce the PAR of the neighborhood with a retail pricing model. Consumers try to minimize their own electricity costs by participating in a non-cooperative game for optimum energy consumption and storage management. In this algorithm, the price signal is received by the consumers from the utility through a dedicated communication link. When consumers receive the price signal, they optimize their local energy consumption individually and send it to the energy provider. Based on the new aggregated energy consumption, the utility calculates the new electricity price and sends it back to the consumers. This process continues until convergence is obtained. In the results, the PAR value of the system is reduced from 1.87 to 1.33 for the reference (centralized) case, to 1.39 for a case $\overline{\text { Algorithm } 1 \text { Outline of a simple Nash equilibrium game algo- }}$ rithm.

1: The aggregator initializes the game by determining the aggregated area profiles and/or the area electricity price.

\section{2: repeat}

3: All users receive the necessary information (area profile and/or electricity price) from the aggregator.

4: Users optimize their payoff functions by minimizing their electricity bills and/or maximizing the incentive gains.

5: Users send to the aggregator the determined individual home consumption profiles.

6: The aggregator receives the updated home profiles and updates the aggregated area profile and/or area electricity price.

7: The aggregator sends the updated data to the all users again.

8: until convergence is achieved, when nobody changes its decision anymore.

with DR and battery storage, and to 1.65 for a case with DR but without battery storage.

In [99], a non-cooperative game is developed to control the charge and discharge of household batteries. Consumers schedule their household appliances depending on the electricity price during the day and charge their batteries with residual electric power (i.e., power not used to supply other loads). Consumers can then use the electric energy from their battery during on-peak hours. Therefore, two pricing schemes are determined. The first is an RTP scheme for household appliances, and the second is the charging price for the battery charging game to encourage consumers to charge their batteries. The charging price is lower than the regular pricing tariffs, but as charging requests increase, this price comes close to the regular price and becomes less attractive. Consumers define their charging strategies based on their earliest starting time, deadlines, and the amount of requested power for charging. Depending on the surplus energy, load, and the state-of-charge of the batteries, the households optimize their payoffs. The proposed game is tested on three houses and is compared with a reference case.

In [100], a scheduling game is proposed for a neighborhood area. Consumers pay the same average daily unit price, and their costs are proportional to their electricity consumption. Consumers receive the TOU rate in order to establish the initial schedule of their appliances. They then receive the scheduling plans of other consumers. Based on the aggregated consumption, a dynamic price rate is calculated according to the TOU price by each smart home. Using this price, consumers optimize the schedule of their appliances to decrease the overall electricity cost of the neighborhood. The game continues until consumers make no more change in their scheduling plan. Results for the distributed coordination model return a total cost of $£ 36.69$, against $£ 38.20$ for selfish scheduling over the simulation duration.

Overall, GT appears as a promising tool for residential load management, and especially for decentralized coordination. 
Smart homes (players) control their electricity profile to increase their payoff function, i.e., to minimize their own electricity costs. This type of game is defined as a non-cooperative game [125], where players only focus on their own benefits. Games may also be designed in a cooperative way, as in [126], where players can form coalitions to reach higher individual payoffs while increasing the total gain for the group. However, due to fairness concerns, coalitions are not permitted in most countries. GT has the advantage of providing flexible games, where the participation of new players does not require changes in the game. However, frequent message exchanges are required with decentralized coordination.

\subsubsection{Optimization techniques}

In HEMS, optimization techniques are typically used to allocate the run time of household appliances over a given time horizon and with a specific objective. The goal generally is to decrease electricity bills or the PAR ratio to obtain flatter load curves. In the literature, problems can take into account grid conditions (e.g., congestion) in the optimization. Formulations can also consider stochastic problems (e.g., with uncertainty on consumption [85] and renewable generation [101]), multiple objectives $[102,103]$, or other objectives such as maintaining voltage stability [104] or decreasing active power losses [105].

Optimization problems are typically formulated as follows, for a simple decentralized case:

$$
\begin{array}{ll}
\text { minimize } & \sum_{h=1}^{H} P(n, h) \cdot C(h) \\
\text { subject to } & P(n, h) \in \Psi(n, h)
\end{array}
$$

For centralized case, the equation becomes:

$$
\begin{array}{cl}
\text { minimize } & \sum_{n=1}^{N} \sum_{h=1}^{H} P(n, h) \cdot C(h) \\
\text { subject to } & \left\{\begin{array}{l}
P(n, h) \in \Psi(n, h), \forall n \\
\sum_{n=1}^{N} P(n, h) \in \Phi(n, h)
\end{array}\right.
\end{array}
$$

where, $P(n, h)$ is the power consumption of house $n$ at time $h$, and $C(h)$ is the price at time $h$. Equation (5) represents the constraints set for smart homes, where $\Psi$ represents the set of feasible power values (e.g., due to the operation time limits of appliances). Equation (7) represents the constraints set for smart homes and the grid, where $\Phi$ represents the set of feasible power values (e.g., due to the operation time limits of the electricity network [56, 61]. As mentioned earlier, other objectives and constraints may be considered [57, 127]. For decentralized optimization, typical objective formulations only sum on $h$ and not on $n$, as each home optimizes its own consumption.

A few selected papers using optimization are now reviewed. In [102], a multi-objective problem aims for cost minimization and load factor maximization. The forecast area load profile is used in a fitness function to optimize electricity usage with a multi-objective genetic algorithm. Penalty and rebate terms are generated by the utility based on a normal distribution curve over the load. As a uniform load distribution is desired, customers pay a penalty or receive a rebate depending on the difference between their load and the curve. Compared to the base case, cost reductions reach $74 \%$ and PAR reductions $42 \%$.

In [105], the optimization problem aims to minimize the users electricity bill, and considers the cost of active power losses, as well as the need to avoid line overload. Investigations focus on the optimal coordination of residential resources, in a distributed fashion, and consider private objectives as well as objectives common to all consumers (here, minimizing losses). Numerical examples show that the proposed decentralized algorithm achieves results similar to what is obtained with a reference centralized algorithm. However, with this algorithm, when losses are considered in the optimization, losses decrease by $4.2 \%$.

Overall, optimization techniques are commonly used in energy management studies, and have the advantage of providing optimal or near optimal solutions, whether it is for individual customers in a selfish fashion, or for entire neighborhoods with coordination. Drawbacks of these techniques are similar the ones of centralized coordination (both are commonly combined). They include high computational requirements that increase with problem size, and the significant detailed information required on end-user resources, which may raise some privacy issues. A more comprehensive study focused on optimization algorithms used for DR can be found in [10].

\section{Discussion}

\subsection{Overview of the state-of-the-art}

HEMS are an important development in the smart grid concept, to control household loads, generation, and storage devices. With DR programs, end-users are no longer considered as passive participants; they can actively participate in electricity markets (directly or through aggregators) and schedule appliance run times to reduce their electricity consumption and bills with limited impact on their comfort. Appliance scheduling does not only provide benefits for end-users, but also for utilities. For example, utility companies are responsible for providing electric energy to consumer at all times, including during peaks when utilities need to generate more (or purchase additional) power. However, demand peaks occur only for short durations in a year, and the additional and usually expensive generation capacity [128] remains idle most of the time during the year. Other applications of DR lie in the provision of ancillary services by the neighborhood to the utility. Utility companies thus use "smart" pricing mechanisms or incentives to influence customers to change their consumption patterns, and hence reduce peak load and, at the same time, enable end-users to reduce their electricity bills. However, when households selfishly schedule their electricity appliances, rebound peaks may appear at unexpected hours [67]. To avoid this situation, coordinating smart homes is an important requirement for neighborhood energy management, especially when considering DG and storage devices. 
Several aspects should be considered when comparing approaches to neighborhood energy management: pricing mechanisms, coordination structures, and coordination techniques. Financial mechanisms are basic tools for utilities to help shape load profiles, through specific pricing schemes or incentive mechanisms. The coordination structure of a neighborhood can be organized around a single entity - a utility or third-party like an aggregator - or by multiple households interacting with each other to take decisions. Coordination mechanisms can then enable strategic energy management, e.g., to prevent the emergence of a rebound peak.

To avoid demand peaks, utilities can resort to various mechanisms that provide an incentive for the end-user to modify electricity consumption. Mechanisms can be based on an incentive (IBP) the customers receive when they reduce their demand, or on specific pricing schemes (PBP, such as TOU or RTP) designed to favor electricity consumption during low-demand periods. While IBP comparatively provide a higher level of confidence for the utility in terms of load reduction, PBP have the advantage of requiring less enabling technologies. On the other hand, complex pricing schemes may not be accepted by all customers, who may suffer for increased bills if they are not able to properly understand how to suitably adapt their consumption.

These mechanisms by themselves are however insufficient to enable efficient neighborhood-level coordination. Communication and coordination is enabled through various structures. In centralized coordination, a central operator can directly optimize appliances schedules for each household or can influence customers by sending price signals, as in [14]. Such coordination typically has better performance than other structures. Having access to all required information, the central entity is able to find the optimal schedule for the entire neighborhood area, or for each individual end-user. However, the scalability of such approaches is limited, as they require significant computational resources for large neighborhood areas.

Algorithms with variable degrees of decentralization are also able to coordinate households scheduling processes, by enabling end-users to exchange information about their consumption profiles, as in [129]. Rather than sending all information to a central entity, end-users can only share selected information and decide on a management strategy themselves. Three types of decentralized coordination may then be distinguished, depending on the independence level from the central entity: fully-dependent, partially-independent and fully-independent (see Table 6):

- The fully-dependent one is the most commonly studied structure, where the central entity only influences the consumers with a price signal and transmits information on the aggregated electricity profile of the area.

- In partially-dependent structures, customers communicate with each other by sharing information about their decisions. The central entity influences customers by calculating the electricity price according to the aggregated consumption profile. This central entity enables the utility not to disclose information on its profits.
- The fully-independent structure is the least studied method so far. Customers have the ability to communicate with each other directly and no central entity is used in the decision-making process.

The main differences between these approaches are thus the degree of centralization of information, and the resulting performance (e.g., costs and PAR). While decentralized structures tend to return less efficient results than centralized ones, they better respect the need for privacy of the customers, which is a growing concern [130]. End-users prefer not to share too much information with their neighbors, as it can give details about their life habits.

In terms of coordination techniques, three main types of algorithms are used in the literature: MAS, GT, and optimization. While they are not an algorithm per se, MAS have the advantage of inherently enabling advanced, distributed coordination between homes. Moreover, MAS enable modeling each component or agent separately and define their interactions, as in a real system. Optimization is commonly used to determine optimal schedules, either for individual smart homes or for the entire neighborhood. Various objectives (e.g., costs, losses) may be used, together with multiple sets of user or system-level constraints. As optimization is commonly used with centralized coordination, both approaches suffer from a limited scalability to large system dimensions. Game theory is another approach that provides decision-making ability to independent players $[125,131]$, i.e., smart homes, whether the game is cooperative or not $[99,98]$. Like MAS, GT is especially suitable for decentralized coordination, and can easily include new players to the game. However, the difficulty to reach an equilibrium state in a large system increases with its size.

Table 7 summarizes the studies analyzed in the previous sections. An analysis of this table shows that PBP are the most commonly used DR type for both centralized and decentralized coordination studies. Decentralized coordination is more frequently studied at the neighborhood level than centralized approaches. Among decentralized coordination papers, while the fully-dependent method is the most used, the fully-independent method is little researched so far, due to the difficulty in obtaining efficient results with limited computation and communication resources. Regarding coordination techniques, optimization is clearly the most commonly used. However, studies mostly focus on deterministic problem solving, and few consider the uncertainty on load, generation and consumer behavior. While MAS and GT have recently been popular tools in power system research, they are still little used for the coordination of multiple smart homes. Studies also typically test techniques on small-scale system, with less than 100 appliances. Only a few validate their approach on large systems with over 1000 appliances. Lastly, although some studies consider RES and storage systems, these resources are usually located at the community scale, and not in individual houses. Moreover, most papers do not focus on maximizing the local use of RES but rather on minimizing costs. 
Table 6: Comparison of coordination structures

\begin{tabular}{|c|c|c|c|c|}
\hline \multirow{2}{*}{ Properties } & \multirow{2}{*}{ Centralized } & \multicolumn{3}{|c|}{ Decentralized } \\
\hline & & Fully-depend. & Partially-independ. & Fully-independ. \\
\hline Communication & Customer via utility & Customer via utility & $\begin{array}{l}\text { Customer via cus- } \\
\text { tomer and/or utility }\end{array}$ & Customer via customer \\
\hline Decision-maker (optim.) & Utility & $\begin{array}{l}\text { Customer with or } \\
\text { without utility }\end{array}$ & $\begin{array}{l}\text { Customer with or } \\
\text { without utility }\end{array}$ & Customer \\
\hline Privacy issues & High (customer) & High (customer) & Low (customer) & High (customer and utility) \\
\hline Communication burden & Medium to high & Low & Medium & Medium to high \\
\hline Computation burden & High & Low & Low & Low \\
\hline Iterative process & No & Yes & Yes & Yes \\
\hline Scalability & Limited & Yes & Yes & Yes \\
\hline Number of studies reviewed & High & High & Medium & Low \\
\hline
\end{tabular}

Table 7: Summary of the reviewed studies.

\begin{tabular}{|c|c|c|c|c|c|c|c|c|c|c|c|c|}
\hline \multirow{2}{*}{ Refs. } & \multicolumn{2}{|c|}{ DR type } & \multicolumn{2}{|c|}{ Structures } & \multicolumn{3}{|c|}{ Techniques } & \multicolumn{2}{|c|}{ Resources } & \multicolumn{3}{|c|}{ Appliance number } \\
\hline & IBP & PBP & Central. & Decentr. & MAS & GT & Optim. & RES & Storage & $1-100$ & $101-1,000$ & $>1,000$ \\
\hline$[56]$ & $\checkmark$ & $\checkmark$ & - & - & - & - & $\checkmark$ & - & $\checkmark$ & $\checkmark$ & - & - \\
\hline [34] & $\checkmark$ & $\checkmark$ & - & - & - & - & $\checkmark$ & - & - & $\checkmark$ & - & - \\
\hline$[57]$ & $\checkmark$ & $\checkmark$ & - & - & - & - & $\checkmark$ & $\checkmark$ & $\checkmark$ & $\checkmark$ & - & - \\
\hline$[58]$ & $\checkmark$ & $\checkmark$ & - & - & - & - & $\checkmark$ & - & - & $\checkmark$ & - & - \\
\hline [59] & - & $\checkmark$ & - & - & - & - & $\checkmark$ & - & - & $\checkmark$ & - & - \\
\hline [60] & - & $\checkmark$ & - & - & - & - & $\checkmark$ & $\checkmark$ & - & $\checkmark$ & - & - \\
\hline [61] & - & $\checkmark$ & - & - & - & - & $\checkmark$ & - & - & $\checkmark$ & - & - \\
\hline [62] & - & $\checkmark$ & - & - & - & - & $\checkmark$ & $\checkmark$ & $\checkmark$ & $\checkmark$ & - & - \\
\hline [63] & - & $\checkmark$ & - & - & - & - & $\checkmark$ & $\checkmark$ & $\checkmark$ & $\checkmark$ & - & - \\
\hline [64] & - & $\checkmark$ & - & - & - & - & $\checkmark$ & - & - & $\checkmark$ & - & - \\
\hline [65] & - & $\checkmark$ & - & - & - & - & $\checkmark$ & $\checkmark$ & - & $\checkmark$ & - & - \\
\hline [76] & - & $\checkmark$ & $\checkmark$ & - & - & - & $\checkmark$ & $\checkmark$ & - & - & - & $\checkmark$ \\
\hline [77] & $\checkmark$ & - & $\checkmark$ & - & - & - & - & - & - & $\checkmark$ & - & - \\
\hline [78] & - & $\checkmark$ & $\checkmark$ & - & - & - & $\checkmark$ & - & $\checkmark$ & - & $\checkmark$ & - \\
\hline [79] & - & $\checkmark$ & $\checkmark$ & $\checkmark$ & - & $\checkmark$ & $\checkmark$ & $\checkmark$ & $\checkmark$ & - & - & $\checkmark$ \\
\hline [80] & - & - & $\checkmark$ & - & - & - & $\checkmark$ & $\checkmark$ & $\checkmark$ & $\checkmark$ & - & - \\
\hline [14] & - & $\checkmark$ & $\checkmark$ & - & - & - & $\checkmark$ & - & - & - & - & $\checkmark$ \\
\hline [66] & - & $\checkmark$ & - & $\checkmark$ & - & - & $\checkmark$ & - & - & - & $\checkmark$ & - \\
\hline [84] & - & $\checkmark$ & - & $\checkmark$ & - & - & $\checkmark$ & - & - & - & $\checkmark$ & - \\
\hline [85] & - & $\checkmark$ & - & $\checkmark$ & - & - & $\checkmark$ & $\checkmark$ & $\checkmark$ & - & $\checkmark$ & - \\
\hline [90] & - & $\checkmark$ & - & $\checkmark$ & - & - & - & - & - & $\checkmark$ & - & - \\
\hline [91] & - & $\checkmark$ & - & $\checkmark$ & - & $\checkmark$ & $\checkmark$ & - & - & $\checkmark$ & $\checkmark$ & - \\
\hline [92] & - & $\checkmark$ & - & $\checkmark$ & - & $\checkmark$ & $\checkmark$ & - & - & - & $\checkmark$ & - \\
\hline [86] & - & $\checkmark$ & - & $\checkmark$ & - & $\checkmark$ & $\checkmark$ & $\checkmark$ & $\checkmark$ & - & $\checkmark$ & - \\
\hline [68] & - & $\checkmark$ & - & $\checkmark$ & - & - & $\checkmark$ & - & - & - & $\checkmark$ & - \\
\hline [95] & - & - & - & $\checkmark$ & $\checkmark$ & - & - & $\checkmark$ & $\checkmark$ & $\checkmark$ & - & - \\
\hline [96] & - & $\checkmark$ & - & $\checkmark$ & $\checkmark$ & - & - & $\checkmark$ & $\checkmark$ & - & $\checkmark$ & - \\
\hline [97] & - & $\checkmark$ & - & $\checkmark$ & $\checkmark$ & - & - & $\checkmark$ & $\checkmark$ & - & - & $\checkmark$ \\
\hline [98] & - & $\checkmark$ & $\checkmark$ & $\checkmark$ & - & $\checkmark$ & $\checkmark$ & - & $\checkmark$ & $\checkmark$ & - & - \\
\hline [99] & - & $\checkmark$ & - & $\checkmark$ & - & $\checkmark$ & $\checkmark$ & - & $\checkmark$ & $\checkmark$ & - & - \\
\hline [100] & - & $\checkmark$ & $\checkmark$ & $\checkmark$ & - & $\checkmark$ & $\checkmark$ & - & - & $\checkmark$ & - & - \\
\hline [102] & - & $\checkmark$ & - & $\checkmark$ & - & - & $\checkmark$ & - & - & - & $\checkmark$ & - \\
\hline [105] & - & $\checkmark$ & $\checkmark$ & $\checkmark$ & - & - & $\checkmark$ & $\checkmark$ & - & - & $\checkmark$ & - \\
\hline
\end{tabular}

\subsection{Next steps}

This review has outlined that the coordination of energy consumption of multiple households presents the opportunity to benefit both sides of the electricity grid, i.e., the utility and the consumers. However, multiple challenges remain for future studies. Although this paper does not focus on implementation issues, costs and standardization of enabling technologies are major challenges. For example, high AMI costs are slowing down deployment, and the lack of standardization and interoperability between equipments from different manufacturers makes adequate control of resources difficult at the neighborhood level, and even at the smart home level. Moving toward 
more decentralized architectures may be difficult to justify if the related costs are significant, and the expected benefits remain low, as shown by some reviewed studies [14]. Legislation may also be a barrier in some cases, if it does not permit the use of adequate pricing mechanisms.

In terms of research, challenges are focused on other aspects. Firstly, an issue for DR programs is in maintaining user comfort preferences at the desired level. Even if smart appliances are set up and DR programs are implemented, the system generally defaults to idle mode because of the end-users, as reported in [132]. For customers, the main purpose of DR programs is to schedule their electricity appliances in order to decrease electricity cost, without significantly affecting their comfort. When the impact on appliance operation causes discomfort or if the expected benefit is too low, consumers tend to turn-off the DR programs. Sociological aspects of end-user behaviors are thus crucial to the success of DR programs. However, although this issue is well studied for a single household, it has not yet been carefully investigated for neighborhood areas. Additionally, competition among end-users, e.g., in the form of a game with a ranking in the neighborhood, could provide another lever to increase DR participation. Smart neighborhoods must thus be considered as cyber-physical-social systems [133].

Privacy is another growing concern. As discussed above, optimal approaches typically require access to a lot of information on end-users and their loads. Such information can reveal customer habits, something most would prefer to avoid. Finding a compromise between performance and privacy is thus a challenge.

Network issues could also be further investigated. For example, the impact of communication delays is usually not considered, especially for distributed algorithms requiring frequent iterations, and where asynchronous messages could cause difficulties. The scalability of the proposed methods also remains problematic, as has not been thoroughly studied so far, for both centralized and decentralized methods.

Another important issue is the integration of residential DG and storage systems into the electricity grid. Such resources are essential for the self-sufficiency of individuals and $\mathrm{CO}_{2}$ emission reduction. However, even though these units are studied in single residential applications, their integration in multiple household areas has not been studied in details. One may also consider DG and storage as alternatives to DR. A comparison can be done when considering payback time. For example, battery systems need to be charged frequently to facilitate the integration of RES. However, frequently charging and discharging a battery significantly decreases its lifetime, which is not the case of DR programs. Moreover, the impact of different penetration rates on performance metrics e.g., (costs, PAR, etc.) for both DG and storage could also be investigated.

A related issue is the accuracy of forecasts, for both loads (especially for such variable load profiles) and DG output. Accurate forecasts are required for adequate scheduling of loads, generation and storage, and errors can lead to increased costs and loss of comfort. Forecasts of baseline net load are also required in many scheduling methods, especially for determining the end-user revenue after he/she has reduced the load.
Scheduling algorithms capable of handling uncertainty, e.g., using robust optimization, are also relatively little studied when applied to smart homes and neighborhoods. Ultimately, solving these issues is required to enable the islanding of community microgrids without requiring oversized DG and storage.

Although many authors mention environmental problems and decreasing $\mathrm{CO}_{2}$ emissions, strategies that actually consider them are little discussed in studies germane to electricity grid operations. Efficient energy management at the home and neighborhood level holds significant potential for limiting emissions, as residential electricity consumption represents a significant share of the total electricity consumption of most countries. However, for now, end-users are scheduling their appliances solely depending on costs. Utilities would thus need to provide information about the $\mathrm{CO}_{2}$ emissions resulting from the used generation sources [134]. Another solution would be to integrate emissions in prices, which would require using a form of carbon tax.

Although the presented studies propose promising results for the neighborhood area coordination, there is no easy way to compare them in terms of performance and computation/communication requirements. The presented system structures, pricing tariffs, objectives and constraints which are used as basis of these studies are different. Therefore, benchmark test systems should be developed to enable comparisons of the proposed methodologies.

Finally, feedback from actual implementations, whether in laboratory testbenches or in demonstration experiments, is insufficiently documented in scientific literature. Although confidentiality issues often have to be solved, the research community could certainly benefit from these results. For example, machine learning could be used for scheduling, but the lack of relevant data is a barrier to development in this field.

\section{Conclusion}

In this paper, recent research studies in the area of energy management of smart homes were reviewed, with a focus on the coordination structures and techniques used for neighborhood areas. The reviewed systems rely on various DSM/DR programs as well as on the scheduling of household appliances, generation and storage devices. Although DR programs combined with DG and storage devices propose promising solutions for smart homes, even better results may be obtained when multiple households are considered. Proper coordination is however required to avoid undesiderable side effects such as rebound peaks. Centralized and decentralized coordination structures were reviewed and compared, as well as different coordination techniques. Results showed that coordination can provide both costs and peak demand reduction, with limited impact on end-users comfort. Coordination thus enables all players, including utilities and aggregators, to benefit from the appropriate control of residential resources. Nevertheless, several issues were highlighted and need to be addressed to enable the deployment of efficient, secure and reliable home energy management systems considering the coordination of multiple smart homes, in interaction with utilities and aggregators. The authors hope 
that this work and its conclusions can be used by researchers and engineers when designing new methods and systems targeted at neighborhoods.

\section{References}

[1] Farhangi H. The path of the smart grid. IEEE Power and Energy Magazine 2010;8(1):18-28.

[2] Boyle G. Renewable electricity and the grid: the challenge of variability. Earthscan; 2012.

[3] Gungor VC, Sahin D, Kocak T, Ergut S, Buccella C, Cecati C, et al. Smart grid technologies: Communication technologies and standards. IEEE Transactions on Industrial Informatics 2011;7(4):529-39.

[4] Rahimi F, Ipakchi A. Demand response as a market resource under the smart grid paradigm. IEEE Transactions on Smart Grid 2010;1(1):82-8.

[5] Khan AA, Razzaq S, Khan A, Khursheed F, et al. HEMSs and enabled demand response in electricity market: an overview. Renewable and Sustainable Energy Reviews 2015;42:773-85.

[6] Gyamfi S, Krumdieck S, Urmee T. Residential peak electricity demand responsehighlights of some behavioural issues. Renewable and Sustainable Energy Reviews 2013;25:71-7.

[7] Zipperer A, Aloise-Young PA, Suryanarayanan S, Roche R, Earle L, Christensen D, et al. Electric energy management in the smart home: Perspectives on enabling technologies and consumer behavior. Proceedings of the IEEE 2013;101(11):2397-408.

[8] Soares A, Gomes Á, Antunes CH. Categorization of residential electricity consumption as a basis for the assessment of the impacts of demand response actions. Renewable and Sustainable Energy Reviews 2014;30:490-503.

[9] Li X, Wen J. Review of building energy modeling for control and operation. Renewable and Sustainable Energy Reviews 2014;37:517-37.

[10] Vardakas JS, Zorba N, Verikoukis CV. A survey on demand response programs in smart grids: Pricing methods and optimization algorithms. IEEE Communications Surveys Tutorials 2015;17(1):152-78.

[11] Haider HT, See OH, Elmenreich W. A review of residential demand response of smart grid. Renewable and Sustainable Energy Reviews 2016;59:166-78.

[12] Sechilariu M, Wang BC, Locment F. Supervision control for optimal energy cost management in DC microgrid: Design and simulation. International Journal of Electrical Power \& Energy Systems 2014;58:140-9.

[13] Roozbehani M, Dahleh MA, Mitter SK. Volatility of power grids under real-time pricing. IEEE Transactions on Power Systems 2012;27(4):1926-40.

[14] Hansen TM, Roche R, Suryanarayanan S, Maciejewski AA, Siegel HJ. Heuristic optimization for an aggregator-based resource allocation in the smart grid. IEEE Transactions on Smart Grid 2015;6(4):1785-94.

[15] Swan LG, Ugursal VI. Modeling of end-use energy consumption in the residential sector: A review of modeling techniques. Renewable and Sustainable Energy Reviews 2009;13(8):1819-35.

[16] Grandjean A, Adnot J, Binet G. A review and an analysis of the residential electric load curve models. Renewable and Sustainable Energy Reviews 2012;16(9):6539-65.

[17] Muratori M, Roberts MC, Sioshansi R, Marano V, Rizzoni G. A highly resolved modeling technique to simulate residential power demand. Applied Energy 2013;107:465-73.

[18] Costanzo GT, Zhu G, Anjos MF, Savard G. A system architecture for autonomous demand side load management in smart buildings. IEEE Transactions on Smart Grid 2012;3(4):2157-65.

[19] Miguel P, Neves L, Martins AG. Methodology to simulate the impact of a large deployment of a residential energy management system in the electricity grid. Electric Power Systems Research 2014;116:399-407.

[20] Chen C, Wang J, Heo Y, Kishore S. MPC-based appliance scheduling for residential building energy management controller. IEEE Transactions on Smart Grid 2013;4(3):1401-10.

[21] Agnetis A, de Pascale G, Detti P, Vicino A. Load scheduling for household energy consumption optimization. IEEE Transactions on Smart Grid 2013;4(4):2364-73.

[22] Zehir MA, Bagriyanik M. Demand side management by controlling refrigerators and its effects on consumers. Energy Conversion and Management 2012;64:238-44.
[23] Bozchalui MC, Hashmi SA, Hassen H, Cañizares CA, Bhattacharya K. Optimal operation of residential energy hubs in smart grids. IEEE Transactions on Smart Grid 2012;3(4):1755-66.

[24] National Energy Technology Laboratory, U.S. Department of Energy . Advanced metering infrastructure. Tech. Rep.; 2008. URL https://www.smartgrid.gov/files/advanced\_metering\ _infrastructure \_02-2008.pdf.

[25] Elzabadani H, Helal A, Abdulrazak B, Jansen E. Self-sensing spaces: smart plugs for smart environments. In: Proceedings of the 3rd International Conference on Smart Homes and Health Telematics. 2005, p. $91-8$.

[26] Hu Q, Li F. Hardware design of smart home energy management system with dynamic price response. IEEE Transactions on Smart Grid 2013;4(4):1878-87.

[27] Aldrich FK. Inside the Smart Home; chap. Smart Homes: Past, Present and Future. London: Springer London. ISBN 978-1-85233-854-1; 2003, p. 17-39.

[28] Special issue: The smart home. Proceedings of the IEEE 2013;101(11).

[29] Frizell S. This startup is trying to createand controlthe internet of your home. 2014. URL http://time.com/2926400/ at-your-service/.

[30] Popular Mechanics . Smart house: Your so-called sci-fi life. 2009. URL http://www.popularmechanics.com/technology/ gadgets/a4109/4216434/.

[31] Kostková K, Omelina L, Kyčina P, Jamrich P. An introduction to load management. Electric Power Systems Research 2013;95:184-91.

[32] Zhou K, Yang S. Demand side management in China: The context of chinas power industry reform. Renewable and Sustainable Energy Reviews 2015;47:954-65.

[33] Macedo M, Galo J, De Almeida L, Lima AdC. Demand side management using artificial neural networks in a smart grid environment. Renewable and Sustainable Energy Reviews 2015;41:128-33.

[34] Sethaolo D, Xia X, Zhang J. Optimal scheduling of household appliances for demand response. Electric Power Systems Research 2014;116:24-8.

[35] Lee M, Aslam O, Foster B, Kathan D, Kwok J, Medearis L, et al. Assessment of demand response and advanced metering. Tech. Rep.; Federal Energy Regulatory Commission; 2011. URL http: //www. ferc.gov/ legal/staff-reports/2010-dr-report.pdf.

[36] Chen C, Wang J, Kishore S. A distributed direct load control approach for large-scale residential demand response. IEEE Transactions on Smart Grid 2014;29(5):2219-28.

[37] Shafiei SE, Knudsen T, Wisniewski R, Andersen P. Data-driven predictive direct load control of refrigeration systems. IET Control Theory \& Applications 2015;9(7):1022-33.

[38] Niu W, Li Y. Uncertain optimization decision of interruptible load in demand response program. In: IEEE Innovative Smart Grid Technologies Asia (ISGT Asia). IEEE; 2014, p. 675-9.

[39] Lee SS, Lee HC, Yoo TH, Noh JW, Na YJ, Park JK, et al. Demand response prospects in the south korean power system. In: IEEE Power and Energy Society General Meeting. IEEE; 2010, p. 1-6.

[40] Homaee O, Zakariazadeh A, Jadid S. Real time voltage control using emergency demand response in distribution system by integrating advanced metering infrastructure. Journal of Renewable and Sustainable Energy 2014;6(3).

[41] Aalami H, Yousefi G, Moghadam MP. Demand response model considering EDRP and TOU programs. In: IEEE/PES Transmission and Distribution Conference and Exposition. IEEE; 2008, p. 1-6.

[42] Aalami H, Moghaddam MP, Yousefi G. Demand response modeling considering interruptible/curtailable loads and capacity market programs. Applied Energy 2010;87(1):243-50.

[43] Pavlak GS, Henze GP, Cushing VJ. Optimizing commercial building participation in energy and ancillary service markets. Energy and Buildings 2014;81:115-26.

[44] Meyn SP, Barooah P, Busic A, Chen Y, Ehren J. Ancillary service to the grid using intelligent deferrable loads. IEEE Transactions on Automatic Control 2015;60(11):2847-62.

[45] Roche R. Agent-based architectures and algorithms for energy management in smart grids. Ph.D. thesis; Univ. Technol. Belfort-Montbéliard, Belfort, France; 2012.

[46] Albadi MH, El-Saadany E. Demand response in electricity markets: An 
overview. In: IEEE Power Engineering Society General Meeting; vol. 2007. 2007, p. 1-5.

[47] Khajavi P, Abniki H, Arani A. The role of incentive based demand response programs in smart grid. In: 10th International Conference on Environment and Electrical Engineering (EEEIC). IEEE; 2011, p. 1-4.

[48] Hu Z, Kim Jh, Wang J, Byrne J. Review of dynamic pricing programs in the us and europe: Status quo and policy recommendations. Renewable and Sustainable Energy Reviews 2015;42:743-51.

[49] Ontario Energy Board . Electricity prices. 2016. Accessed Mar. 2016.; URL http://www.ontarioenergyboard.ca/ oeb/Consumers/Electricity/Electricity $\ \% 20$ Prices/.

[50] Hammerstrom D, Ambrosio R, Brous J, Carlon T, Chassin D, DeSteese J, et al. Pacific Northwest Gridwise testbed demonstration projects. Tech. Rep.; Pacific Northwest National Laboratory; 2007. URL http://sites.energetics.com/MADRI/toolbox/pdfs/ pricing/pnnl\_2007\_pacific\_nw\_gridwise\_olympic \ -peninsula.pdf.

[51] ComEd . The ComEd residential real-time pricing program. 2015. Accessed Feb. 2015.; URL https://www.comed.com/Documents/ HomeSavings-ProgramsIncentives/RRTPGuide200904.pdf.

[52] SDGE . Electricity price. 2016. Accessed Apr. 2016; URL http: //www.sdge.com/business/demand-response/cpp.

[53] Yi P, Dong X, Iwayemi A, Zhou C, Li S. Real-time opportunistic scheduling for residential demand response. IEEE Transactions on Smart Grid 2013;4(1):227-34.

[54] Palensky P, Dietrich D. Demand side management: Demand response, intelligent energy systems, and smart loads. IEEE Transactions on Industrial Informatics 2011;7(3):381-8

[55] Torriti J, Hassan MG, Leach M. Demand response experience in europe: Policies, programmes and implementation. Energy 2010;35(4):157583.

[56] Rastegar M, Fotuhi-Firuzabad M, Aminifar F. Load commitment in a smart home. Applied Energy 2012;96:45-54.

[57] Wu Z, Zhou S, Li J, Zhang XP. Real-time scheduling of residential appliances via conditional risk-at-value. IEEE Transactions on Smart Grid 2014;5(3):1282-91.

[58] Di Giorgio A, Pimpinella L. An event driven smart home controller enabling consumer economic saving and automated demand side management. Applied Energy 2012;96:92-103.

[59] Ozturk Y, Senthilkumar D, Kumar S, Lee G. An intelligent home energy management system to improve demand response. IEEE Transactions on Smart Grid 2013;4(2):694-701.

[60] Erol-Kantarci M, Mouftah HT. Wireless sensor networks for costefficient residential energy management in the smart grid. IEEE Transactions on Smart Grid 2011;2(2):314-25.

[61] Chen Z, Wu L, Fu Y. Real-time price-based demand response management for residential appliances via stochastic optimization and robust optimization. IEEE Transactions on Smart grid 2012;3(4):1822-31.

[62] Fuselli D, De Angelis F, Boaro M, Squartini S, Wei Q, Liu D, et al. Action dependent heuristic dynamic programming for home energy resource scheduling. International Journal of Electrical Power \& Energy Systems 2013;48:148-60.

[63] Chen X, Wei T, Hu S. Uncertainty-aware household appliance scheduling considering dynamic electricity pricing in smart home. IEEE Transactions on Smart Grid 2013;4(2):932-41.

[64] Fakhrazari A, Vakilzadian H, Choobineh FF. Optimal energy scheduling for a smart entity. IEEE Transactions on Smart Grid 2014;5(6):2919-28.

[65] Beaudin M, Zareipour H, Bejestani AK, Schellenberg A. Residential energy management using a two-horizon algorithm. IEEE Transactions on Smart Grid 2014;5(4):1712-23.

[66] Li Y, Ng BL, Trayer M, Liu L. Automated residential demand response: Algorithmic implications of pricing models. IEEE Transactions on Smart Grid 2012;3(4):1712-21.

[67] Roche R, Suryanarayanan S, Hansen TM, Kiliccote S, Miraoui A. A multi-agent model and strategy for residential demand response coordination. In: IEEE PowerTech Eindhoven. IEEE; 2015, p. 1-6.

[68] Chang TH, Alizadeh M, Scaglione A. Real-time power balancing via decentralized coordinated home energy scheduling. IEEE Transactions on Smart Grid 2013;4(3):1490-504.

[69] Kishore S, Snyder LV. Control mechanisms for residential electricity demand in smartgrids. In: First IEEE International Conference on Smart
Grid Communications (SmartGridComm). IEEE; 2010, p. 443-8.

[70] Fan Z, Kulkarni P, Gormus S, Efthymiou C, Kalogridis G, Sooriyabandara $\mathrm{M}$, et al. Smart grid communications: Overview of research challenges, solutions, and standardization activities. IEEE Communications Surveys \& Tutorials 2013;15(1):21-38.

[71] Hansen T, Roche R, Suryanarayanan S, Siegel HJ, Zimmerle D, Young $\mathrm{PM}$, et al. A proposed framework for heuristic approaches to resource allocation in the emerging smart grid. In: IEEE International Conference on Power System Technology (POWERCON). IEEE; 2012, p. 1-6.

[72] Gkatzikis L, Koutsopoulos I, Salonidis T. The role of aggregators in smart grid demand response markets. IEEE Journal on Selected Areas in Communications 2013;31(7):1247-57.

[73] Lan T, Kang Q, An J, Yan W, Wang L. Sitting and sizing of aggregator controlled park for plug-in hybrid electric vehicle based on particle swarm optimization. Neural Computing and Applications 2013;22(2):249-57.

[74] Han S, Han SH, Sezaki K. Design of an optimal aggregator for vehicleto-grid regulation service. In: Innovative Smart Grid Technologies (ISGT). IEEE; 2010, p. 1-8.

[75] Suryanarayanan S, Mancilla-David F, Mitra J, Li Y. Achieving the smart grid through customer-driven microgrids supported by energy storage. In: IEEE International Conference on Industrial Technology (ICIT). 2010, p. 884-90.

[76] Logenthiran T, Srinivasan D, Shun TZ. Demand side management in smart grid using heuristic optimization. IEEE Transactions on Smart Grid 2012;3(3):1244-52.

[77] Niro G, Salles D, Alcântara MV, da Silva LC. Large-scale control of domestic refrigerators for demand peak reduction in distribution systems. Electric Power Systems Research 2013;100:34-42.

[78] Nguyen DT, Le LB. Joint optimization of electric vehicle and home energy scheduling considering user comfort preference. IEEE Transactions on Smart Grid 2014;5(1):188-99.

[79] Tushar MH, Assi C, Maier M, Uddin MF. Smart microgrids: Optimal joint scheduling for electric vehicles and home appliances. IEEE Transactions on Smart Grid 2014;5(1):239-50.

[80] Dai R, Mesbahi M. Optimal power generation and load management for off-grid hybrid power systems with renewable sources via mixed-integer programming. Energy Conversion and Management 2013;73:234-44.

[81] Paterakis NG, Erdin O, Pappi IN, Bakirtzis AG, Catal£o JPS. Coordinated operation of a neighborhood of smart households comprising electric vehicles, energy storage and distributed generation. IEEE Transactions on Smart Grid 2016;7(6):2736-47.

[82] Celik B, Roche R, Bouquain D, Miraoui A. Increasing local renewable energy use in smart neighborhoods through coordinated trading. Energy Engineering; Institution of Engineering and Technology; 2016, p. $217-$ 52.

[83] Ouammi A. Optimal power scheduling for a cooperative network of smart residential buildings. IEEE Transactions on Sustainable Energy 2016;7(3):1317-26.

[84] Chavali P, Yang P, Nehorai A. A distributed algorithm of appliance scheduling for home energy management system. IEEE Transactions on Smart Grid 2014;5(1):282-90.

[85] Guo Y, Pan M, Fang Y, Khargonekar PP. Decentralized coordination of energy utilization for residential households in the smart grid. IEEE Transactions on Smart Grid 2013;4(3):1341-50.

[86] Safdarian A, Fotuhi-Firuzabad M, Lehtonen M. Optimal residential load management in smart grids: A decentralized framework. IEEE Transactions on Smart Grid 2016;7(4):1836-45.

[87] Moon S, Lee JW. Multi-residential demand response scheduling with multi-class appliances in smart grid. IEEE Transactions on Smart Grid 2016;PP(99):1-

[88] Mhanna S, Chapman AC, Verbi G. A fast distributed algorithm for largescale demand response aggregation. IEEE Transactions on Smart Grid 2016;7(4):2094-107.

[89] Mediwaththe CP, Stephens ER, Smith DB, Mahanti A. A dynamic game for electricity load management in neighborhood area networks. IEEE Transactions on Smart Grid 2016;7(3):1329-36.

[90] Chen H, Li Y, Louie RH, Vucetic B. Autonomous demand side management based on energy consumption scheduling and instantaneous load billing: An aggregative game approach. IEEE Transactions on Smart Grid 2014;5(4):1744-54. 
[91] Deng R, Yang Z, Chen J, Asr NR, Chow MY. Residential energy consumption scheduling: A coupled-constraint game approach. IEEE Transactions on Smart Grid 2014;5(3):1340-50.

[92] Mohsenian-Rad AH, Wong VW, Jatskevich J, Schober R, Leon-Garcia A. Autonomous demand-side management based on game-theoretic energy consumption scheduling for the future smart grid. IEEE Transactions on Smart Grid 2010;1(3):320-31.

[93] Samadi P, Mohsenian-Rad H, Wong VW, Schober R. Real-time pricing for demand response based on stochastic approximation. IEEE Transactions on Smart Grid 2014;5(2):789-98.

[94] Mets K, D'hulst R, Develder C. Comparison of intelligent charging algorithms for electric vehicles to reduce peak load and demand variability in a distribution grid. Journal of Communications and Networks 2012;14(6):672-81.

[95] Kyriakarakos G, Piromalis DD, Dounis AI, Arvanitis KG, Papadakis G. Intelligent demand side energy management system for autonomous polygeneration microgrids. Applied Energy 2013;103:39-51.

[96] Kahrobaee S, Rajabzadeh RA, Soh LK, Asgarpoor S. Multiagent study of smart grid customers with neighborhood electricity trading. Electric Power Systems Research 2014;111:123-32.

[97] Fazal R, Solanki J, Solanki SK. Demand response using multi-agent system. In: North American Power Symposium (NAPS). IEEE; 2012, p. $1-6$.

[98] Nguyen HK, Song JB, Han Z. Demand side management to reduce peakto-average ratio using game theory in smart grid. In: IEEE Conference on Computer Communications Workshops. IEEE; 2012, p. 91-6.

[99] Adika CO, Wang L. Non-cooperative decentralized charging of homogeneous households' batteries in a smart grid. IEEE Transactions on Smart Grid 2014;5(4):1855-63.

[100] Zhu Z, Tang J, Lambotharan S, Chin WH, Fan Z. An integer linear programming and game theory based optimization for demand-side management in smart grid. In: IEEE GLOBECOM Workshops. IEEE; 2011, p. $1205-10$.

[101] Jiang L, Low S. Multi-period optimal energy procurement and demand response in smart grid with uncertain supply. In: Decision and Control and European Control Conference (CDC-ECC), 2011 50th IEEE Conference on. IEEE; 2011, p. 4348-53.

[102] Kunwar N, Yash K, Kumar R. Area-load based pricing in DSM through ANN and heuristic scheduling. IEEE Transactions on Smart Grid 2013;4(3):1275-81.

[103] Giusti A, Salani M, Di Caro GA, Rizzoli AE, Gambardella LM. Restricted neighborhood communication improves decentralized demandside load management. IEEE Transactions on Smart Grid 2014;5(1):92101.

[104] Wang D, Parkinson S, Miao W, Jia H, Crawford C, Djilali N. Online voltage security assessment considering comfort-constrained demand response control of distributed heat pump systems. Applied Energy 2012;96:104-14

[105] Juelsgaard M, Andersen P, Wisniewski R. Distribution loss reduction by household consumption coordination in smart grids. IEEE Transactions on Smart Grid 2014:5(4):2133-44.

[106] Chen Y, Lu J, Yu X, Hill DJ. Multi-agent systems with dynamical topologies: Consensus and applications. IEEE Circuits and Systems Magazine 2013;13(3):21-34.

[107] McArthur SD, Davidson EM, Catterson VM, Dimeas AL, Hatziargyriou ND, Ponci F, et al. Multi-agent systems for power engineering applicationspart I: Concepts, approaches, and technical challenges. IEEE Transactions on Power Systems 2007;22(4):1743-52.

[108] Roche R, Lauri F, Blunier B, Miraoui A, Koukam A. Multi-agent technology for power system control. In: Power Electronics for Renewable and Distributed Energy Systems. Springer; 2013, p. 567-609.

[109] Zhao P, Suryanarayanan S, Simoes MG. An energy management system for building structures using a multi-agent decision-making control methodology. IEEE Transactions on Industry Applications 2013;49(1):322-30.

[110] Suryanarayanan S, Rietz R, Mitra J. A framework for energy management in customer-driven microgrids. In: IEEE Power and Energy Society General Meeting. IEEE; 2010, p. 1-4.

[111] Roche R, Idoumghar L, Suryanarayanan S, Daggag M, Solacolu CA, Miraoui A. A flexible and efficient multi-agent gas turbine power plant energy management system with economic and environmental constraints. Applied Energy 2013;101:644-54.

[112] Wooldridge M. An introduction to multiagent systems. John Wiley \& Sons; 2009.

[113] Mao M, Jin P, Hatziargyriou ND, Chang L. Multiagent-based hybrid energy management system for microgrids. IEEE Transactions on Sustainable Energy 2014;5(3):938-46.

[114] Tan Z, Yang P, Nehorai A. An optimal and distributed demand response strategy with electric vehicles in the smart grid. IEEE Transactions on Smart Grid 2014;5(2):861-9.

[115] Von Neumann J, Morgenstern O. Theory of games and economic behavior. Princeton university press; 2007.

[116] Nash JF, et al. Equilibrium points in n-person games. Proc Nat Acad Sci USA 1950;36(1):48-9.

[117] Osborne MJ, Rubinstein A. A course in game theory. MIT press; 1994.

[118] Doubligeris C, Mazumdar R. A game theoretic approach to flow control in an integrated environment with two classes of users. In: Proceedings of the 1988 Computer Networking Symposium. IEEE; 1988, p. 214-21.

[119] Roughgarden T, Tardos É. How bad is selfish routing? Journal of the ACM 2002;49(2):236-59.

[120] MacKenzie AB, Wicker SB. Game theory in communications: Motivation, explanation, and application to power control. In: IEEE Global Telecommunications Conference (GLOBECOM'01); vol. 2. IEEE; 2001, p. 821-6.

[121] Suryanarayanan S. Techniques for accommodating unscheduled flows in electricity networks and markets. In: Power and Energy Society General Meeting - Conversion and Delivery of Electrical Energy in the 21st Century, 2008 IEEE. 2008, p. 1-6.

[122] Tushar W, Zhang JA, Smith DB, Poor HV, Thibaux S. Prioritizing consumers in smart grid: A game theoretic approach. IEEE Transactions on Smart Grid 2014;5(3):1429-38.

[123] Bai L, Xu G, Zheng QP. A game theoretical approach to modeling energy consumption with consumer preference. In: 2014 IEEE PES General Meeting — Conference Exposition. 2014, p. 1-5.

[124] Kirschen D, Strbac G. Fundamentals of Power System Economics. John Wiley \& Sons; 2004. ISBN 9780470020593

[125] Zhu Z, Lambotharan S, Chin WH, Fan Z. A game theoretic optimization framework for home demand management incorporating local energy resources. Industrial Informatics, IEEE Transactions on 2015;11(2):35362.

[126] Zhang N, Yan Y, Su W. A game-theoretic economic operation of residential distribution system with high participation of distributed electricity prosumers. Applied Energy 2015;154:471-9.

[127] Shao S, Pipattanasomporn M, Rahman S. Development of physicalbased demand response-enabled residential load models. Power Systems, IEEE Transactions on 2013;28(2):607-14.

[128] Newsham GR, Bowker BG. The effect of utility time-varying pricing and load control strategies on residential summer peak electricity use: a review. Energy Policy 2010;38(7):3289-96.

[129] Celik B, Roche R, Bouquain D, A. M. Coordinated energy management using agents in neighborhood areas with res and storage. In: IEEE International Energy Conference (EnergyCon). 2016,.

[130] McDaniel P, McLaughlin S. Security and privacy challenges in the smart grid. IEEE Security \& Privacy 2009;7(3):75-7.

[131] Saad W, Han Z, Poor HV, Başar T. Game-theoretic methods for the smart grid: An overview of microgrid systems, demand-side management, and smart grid communications. Signal Processing Magazine, IEEE 2012;29(5):86-105.

[132] Pier Demand Response Research Center . Understanding customer behavior to improve demand response delivery in California. Tech. Rep.; 2007. URL http://poet.lbl.gov/drrc/pubs/drrc-ron-3.pdf.

[133] Liu Z, Yang D, Wen D, Zhang W, Mao W. Cyber-physicalsocial systems for command and control. IEEE Intelligent Systems 2011;26(4):92-6.

[134] Song M, Alvehag K, Widén J, Parisio A. Estimating the impacts of demand response by simulating household behaviours under price and $\mathrm{CO}_{2}$ signals. Electric Power Systems Research 2014;111:103-14. 